\title{
Dust mobilization and transport in the northern Sahara during SAMUM 2006 - a meteorological overview
}

\author{
By PETER KNIPPERTZ ${ }^{*}$, ALBERT ANSMANN ${ }^{2}$, DIETRICH ALTHAUSEN ${ }^{2}$, DETLEF \\ MÜLLER ${ }^{2}$, MATTHIAS TESCHE ${ }^{2}$, EIKE BIERW IRTH ${ }^{1}$, TILMAN DINTER $^{3}$, THOMAS \\ MÜLLER ${ }^{2}$, W OLFGANG VON HOYNINGEN-HUENE ${ }^{3}$, KERSTIN SCHEPANS KI I ${ }^{2,4}$, \\ MANFRED WENDISCH ${ }^{1}$, BERND HEINOLD ${ }^{2}$, KONRAD KANDLER ${ }^{5}$, ANDREAS \\ PETZOLD ${ }^{6}$, LOTHAR SCHÜTZ ${ }^{1}$ and INA TEGEN ${ }^{2}$, ${ }^{1}$ Institute for Atmospheric Physics, Johannes \\ Gutenberg University Mainz, D-55099 Mainz, Germany ${ }^{2}$ Leibniz Institute for Tropospheric Research, Leipzig, \\ Germany ${ }^{3}$ Institute of Environmental Physics, University of Bremen, Bremen, Germany ${ }^{4}$ Leibniz-Institute for Marine \\ Sciences, IfM-Geomar, Kiel, Germany ${ }^{5}$ Institute for Applied Geosciences, Darmstadt University of Technology, \\ Darmstadt, Germany ${ }^{6}$ Institute for Atmospheric Physics, German Aerospace Center, Oberpfaffenhofen, Germany
}

(Manuscript received 13 December 2007; in final form 11 July 2008)

\begin{abstract}
The SAMUM field campaign in southern Morocco in May/June 2006 provides valuable data to study the emission, and the horizontal and vertical transports of mineral dust in the Northern Sahara. Radiosonde and lidar observations show differential advection of air masses with different characteristics during stable nighttime conditions and up to 5-km deep vertical mixing in the strongly convective boundary layer during the day. Lagrangian and synoptic analyses of selected dust periods point to a topographic channel from western Tunisia to central Algeria as a dust source region. Significant emission events are related to cold surges from the Mediterranean in association with eastward passing upper-level waves and lee cyclogeneses south of the Atlas Mountains. Other relevant events are local emissions under a distinct cut-off low over northwestern Africa and gust fronts associated with dry thunderstorms over the Malian and Algerian Sahara. The latter are badly represented in analyses from the European Centre for Medium-Range Weather Forecasts and in a regional dust model, most likely due to problems with moist convective dynamics and a lack of observations in this region. This aspect needs further study. The meteorological source identification is consistent with estimates of optical and mineralogical properties of dust samples.
\end{abstract}

\section{Introduction}

One of the challenges in the quantitative understanding of the dust cycle is the numerical modelling of dust emission and transport occurring at a wide range of spatial scales. Uncertainties in the representation of low-level winds and soil characteristics make the emission a particularly difficult ingredient of dust models. The observational data collected in southern Morocco during the first field campaign in the framework of the Saharan Mineral Dust Experiment (SAMUM; Heintzenberg, 2008) in May and June 2006 provides a unique opportunity to study some of the involved atmospheric processes in detail. For North Africa, the following meteorological systems are of major interest:

(1) On the synoptic-scale (hundreds of kilometres), the most important weather systems are extratropical surface depressions

\footnotetext{
*Corresponding author.

e-mail: knippertz@uni-mainz.de

DOI: $10.1111 /$ j.1600-0889.2008.00380.x
}

during spring, which are often related to southward penetrating upper-level troughs or cut-off lows from Europe or the adjacent Atlantic. Typical examples are Khamsin, Sharav or desert depressions that form in the lee of the Atlas Mountains and then track east- or northeastward causing dust storms along the Mediterranean coast (El Fandy, 1940; Pedgley, 1972; Yaalon and Ganor, 1979). Intense dust storms in the Sahara during winter and spring occur in connection with low-level pressure surges associated with an intensification of anticyclonic conditions over northern Africa (Kalu, 1979). These are related to cold air intrusions from the mid-latitudes and are sometimes enhanced by evaporational cooling (Knippertz and Fink, 2006). The resulting intensification of the Harmattan winds cause localized emissions from preferential sources (Washington and Todd, 2005) and in strong cases long, fast moving dust fronts (Knippertz and Fink, 2006; Slingo et al., 2006).

(2) On the meso-scale (few to several hundred kilometres), density currents driven by the cooling associated with the evaporation of convective precipitation in the hot and dry desert 
air play an important role. Dust storms along the leading edge of a quickly spreading cold pool are often called haboobs and have first been documented for squall-line type convection in the Sudan (Sutton, 1925; Lawson, 1971). Similar features are found over the semi-arid parts of the USA (Idso et al., 1972; Chen and Fryrear, 2002), the Arabian Peninsula (Membery, 1985; Miller et al., 2008) and along the southern side of the Atlas Mountains in Morocco and Algeria (Knippertz et al., 2007). Over the Sahel, the nocturnal acceleration of the monsoon flow in summer can also cause meso-scale dust mobilization (Bou Karam et al., 2008).

(3) On the microscale $(<2 \mathrm{~km})$, dust is mobilized in connection with dry convective mixing in the planetary boundary layer (PBL), which can reach depths of more than $5 \mathrm{~km}$ over arid or semi-arid subtropical land surfaces during the daytime (Gamo, 1996; Flamant et al., 2007). Part of the mixing is realized in form of rotating dust devils and non-rotating convective plumes, which can contribute substantially to dust emissions (Koch and Renno, 2005). Typical conditions for their formation include moderate near-surface wind shear and a large temperature contrast between the surface and the lowest few metres of the atmosphere (Oke et al., 2007). The latter requires intense downward solar radiation, a dry soil and low aerosol optical thickness (AOT; Ansmann et al., 2008b). Another important aspect of the vigorous PBL mixing is the homogenization of dust from different sources and the vertical transport to fairly great heights (up to $5 \mathrm{~km}$ above ground during SAMUM).

This study has three objectives: (a) Provide an overview of the synoptic evolution during the field campaign, and characterize the air masses and meteorological conditions that affected the SAMUM measurements in southern Morocco; (b) Describe some of the particularities of the warm-season PBL over the Sahara as revealed by the in situ and remote sensing measurements during SAMUM, and discuss their implications for the vertical mixing and horizontal transport of dust aerosol; (c) Provide a detailed investigation of the meteorological conditions for dust emission and transport for three selected dusty days (Cases I, II and III), including an identification of source regions. The results of this analysis will be discussed in the light of the mineralogical composition of the dust (Kandler et al., 2008), its optical properties (Petzold et al., 2008) and dust emissions simulated by a regional dust model (Heinold et al., 2008). The paper is structured as follows: Section 2 provides information on the employed data. The three objectives stated above are addressed in Sections 3-5 and Section 6 contains a summary and conclusions.

\section{Data}

\subsection{Study area}

During the SAMUM field campaign (12 May-8 June 2006) in situ and remote sensing observations were collected at the airport

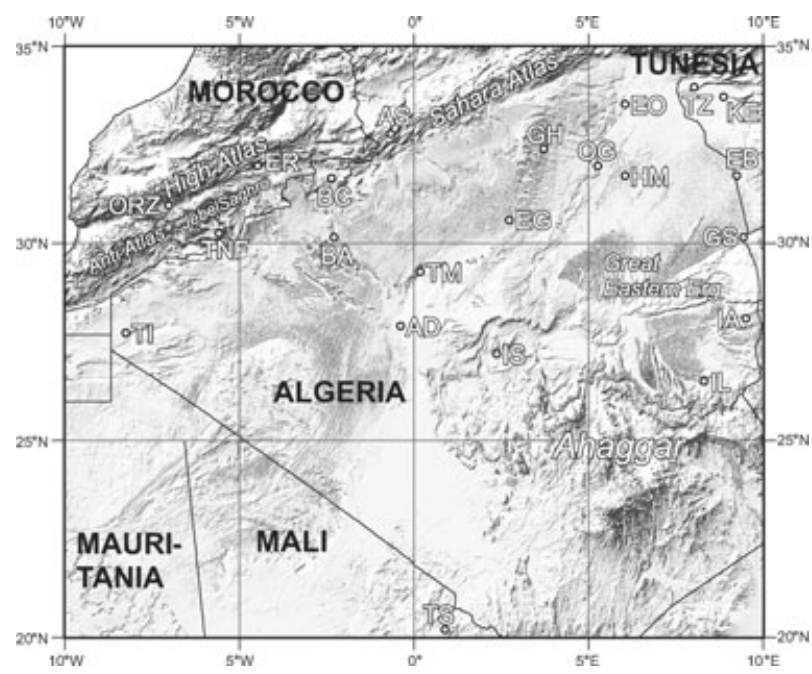

Fig. 1. Geographical overview of the study region. The two SAMUM observation sites ORZ and TNF, and the synoptic stations used in this study are marked (for more information see Table 1).

of Ouarzazate (ORZ hereafter; $30.93^{\circ} \mathrm{N}, 6.90^{\circ} \mathrm{W}, 1133 \mathrm{~m}$ ) and at Tinfou (TNF; $\left.30.25^{\circ} \mathrm{N}, 5.62^{\circ} \mathrm{W}, 680 \mathrm{~m}\right)$. Both stations are located in the Saharan foothills of the High Atlas Mountains (more than $4000 \mathrm{~m}$ ) in southern Morocco (Fig. 1). The two stations are separated by the Anti-Atlas/Jebel Saghro chain (up to $2700 \mathrm{~m}$ ). The climate of the region is semi-arid with annual precipitation on the order of 100-200 $\mathrm{mm}$.

\subsection{Special SAMUM observations}

Fifty standard radiosondes of type RS92 and RS80 (Vaisala, Helsinki, Finland) were launched from ORZ, usually one in the morning and one in the evening. Three lidars were deployed at ORZ, but for this study, only range-corrected backscattering signals at 1064-nm from the six-wavelength aerosol lidar Backscatter Extinction lidar-Ratio Temperature Humidity profiling Apparatus (BERTHA) of the Leibniz Institute for Tropospheric Research at ORZ (Althausen et al., 2000; Tesche et al., 2008) are used in a temporal resolution of $30 \mathrm{~s}$ and a vertical resolution of $60 \mathrm{~m}$. At $1064 \mathrm{~nm}$ the influence of Rayleigh backscattering by air molecules is small and dust features can be well identified. Backscatter by desert dust is almost independent of wavelength and thus particle size. Therefore, backscatter or extinction (lidar ratio is approximately constant) is indicative of dust mass concentration. The scattering and extinction of the laser light within the dust layer causes a decrease in signal strength (after range correction) with height. For example, a typical AOT of 0.4 corresponds to an effective two-way optical depth of 0.8 , which causes an attenuation of the lidar signal of almost $40 \%$ from 1 to $4 \mathrm{~km}$ above ground. We did not correct for this effect and use the lidar signals for a qualitative description of the characteristics and evolution of dust layers only. Due to 
problems with overlap corrections, we do not show signals from the lowest kilometre above the lidar (see Tesche et al., 2008).

Spectral downwelling irradiance was measured at ORZ with a compact radiation measurement system (CORAS) with a spectral resolution of $1 \mathrm{~nm}$ at $500 \mathrm{~nm}$ wavelength (Bierwirth et al., 2008). Sun photometers were deployed at both sites. At ORZ an Aerosol Robotic Network (AERONET; Holben et al., 1998) sun photometer was operated, which measures AOT from 340 to $1640 \mathrm{~nm}$ wavelength (D. Müller, 2008, personal communication). At TNF the AOT was measured at eight different wavelengths using a Cimel Sun Photometer CE 318 (Cimel Electronique; Paris, France) with slightly modified channels (Dinter et al., 2008). In this paper we will only consider AOTs at $500 \mathrm{~nm}$ wavelength. At TNF horizontal visibility was measured continuously with a VPF-710 visibility sensor (Biral, Bristol, UK) with a time resolution of 1 min (Schladitz et al., 2008; Müller et al., 2008) and near-surface wind, temperature, humidity and pressure were recorded every $30 \mathrm{~s}$ using standard meteorological instruments detailed in Knippertz et al. (2007). The results from the dust emission and transport analysis are qualitatively compared to simulations with the regional dust model system LM-MUSCATDES described in Heinold et al. (2008).

\subsection{Other data and analysis tools}

For the regional analysis of dust emission and transport we employ standard synoptic and upper-air station reports (SYN-
OPs and RAOBs) from the Saharan parts of Morocco, Algeria, Tunisia, Libya and Mali distributed by the World Meteorological Organization (WMO; see Fig. 1 and Table 1). In particular three-hourly horizontal visibility measurements from the synoptic station at ORZ are used for a comparison with the SAMUM measurements. These are made with a Mitras transmissometer (Vaisala, Helsinki, Finland) that in the standard configuration only outputs a limited number of values (see Fig. 2b). The largescale circulation over northern Africa is analysed with the help of operational analyses from the European Centre for MediumRange Weather Forecasts (ECMWF) in a horizontal resolution of $0.5^{\circ} \times 0.5^{\circ}$. To identify the origin of air masses reaching the SAMUM region, trajectories were calculated on the basis of 3-D wind fields from the ECMWF using the Lagrangian Analysis Tool (LAGRANTO; Wernli and Davies, 1997). In addition Meteosat Second Generation (MSG) satellite images in the visible (VIS) and thermal infrared (IR) channels, as well as a new MSG dust product are used. The latter is composed of the brightness temperature difference at 12.0-10.8 $\mu \mathrm{m}$ (red) and 10.8-8.7 $\mu \mathrm{m}$ (green), as well as $10.8 \mu \mathrm{m}$ (blue; Schepanski et al., 2007). For more information see http://oiswww. eumetsat.org/WEBOPS/msg_interpretation/index.html.

\section{Synoptic overview}

Figure 2 shows observations of AOT, horizontal visibility and downwelling irradiance over southern Morocco for the entire

Table 1. Synoptic and upper-air stations with station name, abbreviation, country, WMO-number, latitude, longitude and elevation asl

\begin{tabular}{lllllll}
\hline WMO-no. & Name & Abbr. & Country & Lat. $\left({ }^{\circ} \mathrm{N}\right)$ & Lon. $\left({ }^{\circ} \mathrm{E}\right)$ & Elev. $(\mathrm{m})$ \\
\hline 60210 & Errachidia & ER & Morocco & 31.93 & -4.40 & 1042 \\
60265 & Ouarzazate & ORZ & Morocco & 30.93 & -6.90 & 1140 \\
60559 & El Oued & EO & Algeria & 33.50 & 6.12 & 69 \\
60560 & Ain Sefra & AS & Algeria & 32.77 & -0.60 & 1059 \\
60566 & Ghardaia & GH & Algeria & 32.38 & 3.82 & 469 \\
60571 & Bechar & BC & Algeria & 31.62 & -2.23 & 816 \\
60580 & Ouargla & OG & Algeria & 31.92 & 5.40 & 148 \\
60581 & Hassi Messaoud & HM & Algeria & 31.67 & 6.15 & 144 \\
60590 & El Golea & EG & Algeria & 30.57 & 2.87 & 403 \\
60602 & Beni Abbes & BA & Algeria & 30.13 & -2.17 & 505 \\
60607 & Timimoun & TM & Algeria & 29.25 & 0.28 & 317 \\
60611 & In Amenas & IA & Algeria & 28.05 & 9.63 & 562 \\
60620 & Adrar & AD & Algeria & 27.88 & -0.28 & 283 \\
60630 & In Salah & IS & Algeria & 27.20 & 2.47 & 269 \\
60640 & Illizi & IL & Algeria & 26.50 & 8.42 & 544 \\
60656 & Tindouf & TI & Algeria & 27.67 & -8.13 & 439 \\
60760 & Touzeur & TZ & Tunisia & 33.92 & 8.10 & 93 \\
60764 & Kebili & KE & Tunisia & 33.70 & 8.97 & 46 \\
60780 & El Borma & EB & Tunisia & 31.68 & 9.17 & 259 \\
61202 & Tessalit & TS & Mali & 20.20 & 0.98 & 491 \\
62103 & Ghadames & GS & Libya & 30.13 & 9.50 & 347 \\
\hline
\end{tabular}




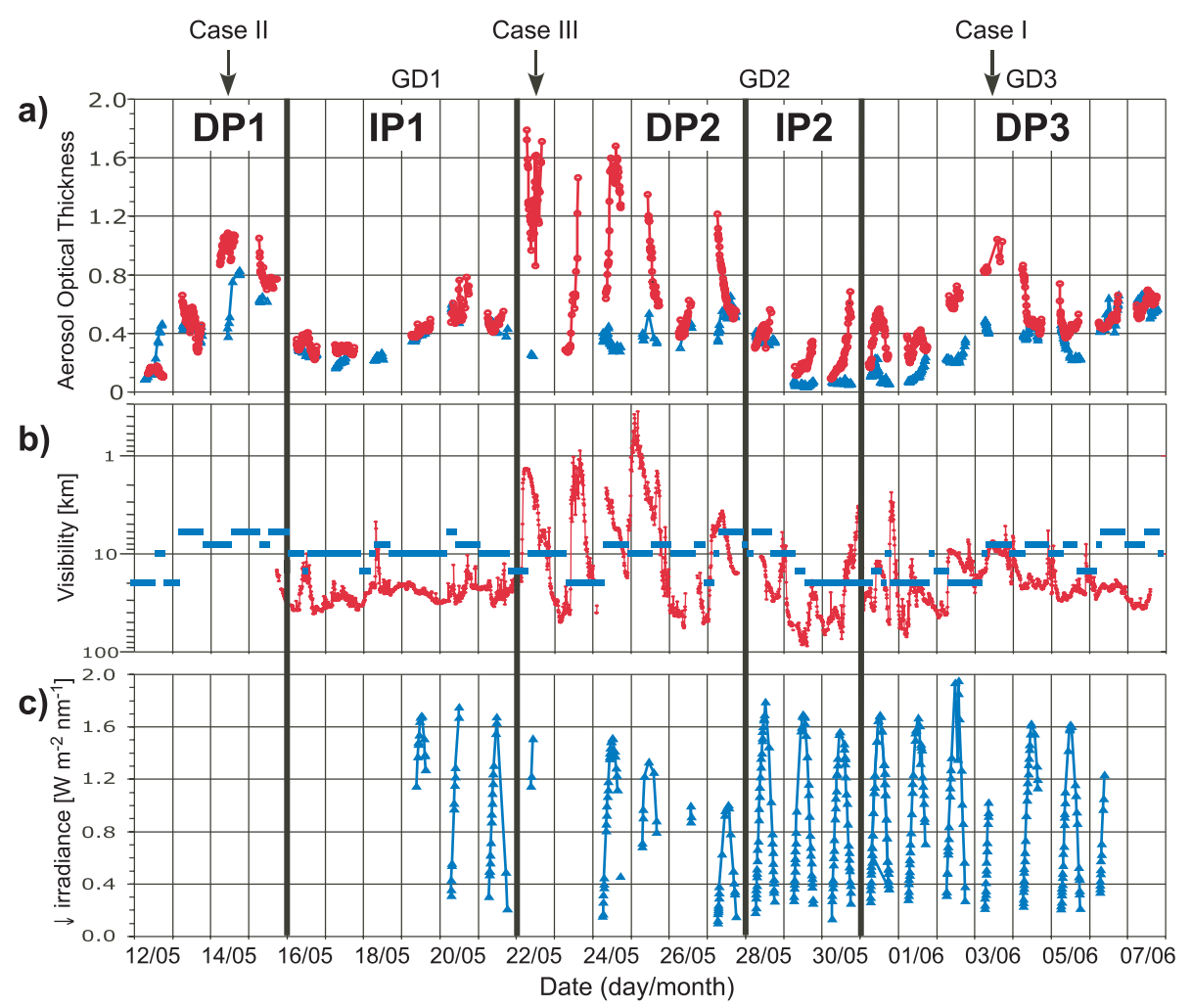

Fig. 2. Optical measurements at ORZ (blue) and TNF (red) during 12 May to 7 June 2006. (a) Sun photometer measurements of AOT at $500 \mathrm{~nm}$, (b) horizontal visibility (note the inverse logarithmic ordinate) and (c) spectral downwelling irradiance at $500 \mathrm{~nm}$ measured with a spectral resolution of $1 \mathrm{~nm}$ (only times that are flagged 'cloud free' by AERONET are shown). For more information on the used data, see Section 2. The cases analysed in Section 5, the 'SAMUM golden days' (GD), and the dust and intermediate phases (DPs and IPs) discussed in Section 3 are indicated.

campaign. Since all three quantities were strongly influenced by mineral desert dust (e.g. Kandler et al., 2008), these timeseries are used to subdivide the SAMUM period in three dust phases (DPs) and two intermediate phases (IPs) that will be described in the following subsections. Maps of geopotential height at 300 and $925 \mathrm{hPa}$ together with 2-d backward trajectories will be presented to characterize the large-scale circulation and air masses during the different phases (Fig. 3). Special attention will be paid to the three 'SAMUM golden days' (GDs) 19 and 28 May, and 4 June 2006, when the Terra satellite with the Multiangle Imaging SpectroRadiometer (MISR) passed over the SAMUM region and when intensive ground and aircraft observations were conducted (Heintzenberg, 2008).

\subsection{Dust phase 1 (12-15 May 2006) and intermediate phase 1 (16-21 May 2006)}

The first dust phase (DP1) reveals a distinct increase in AOT from about 0.2 on 12 May to around 0.7 at ORZ and to more than 1 at TNF on 14 and 15 May (Fig. 2a) accompanied by a decrease in horizontal visibility at ORZ (Fig. 2b). Irradiance was not yet measured during this period. The large-scale circulation during DP1 was dominated by an upper-level short-wave that moved across northwestern Africa between 11 and 14 May and triggered the formation of a lee cyclone (marked ' $L$ ' in Fig. 3a; see Egger et al., 1995). The fairly low AOTs on 12 May were associated with air masses of predominantly Atlantic origin (trajectories in Fig. 3a), while on the following days dusty air from eastern and central Algeria was advected into southern Morocco along the northern flank of the low-level cyclone (not shown). This event will be discussed in detail in Section 5.2.

Between 16 and 21 May northwestern Africa was dominated by an upper-level ridge and calm sunny weather (Fig. 3b). This period is therefore termed intermediate phase 1 (IP1). A persistent surface high with core over the eastern Atlas steered air from eastern and central Algeria towards southern Morocco. This air mass was moderately dusty with AOT values below 0.5 , horizontal visibility around $10-20 \mathrm{~km}$ and downwelling irradiances at mid-day of about $1.7 \mathrm{~W} \mathrm{~m}^{-2} \mathrm{~nm}^{-1}$ for most of the period (Fig. 2). Part of the dustiness was related to locally generated dry-convective dust plumes (Ansmann et al., 2008b). The first golden day (GD1) falls into this period. 

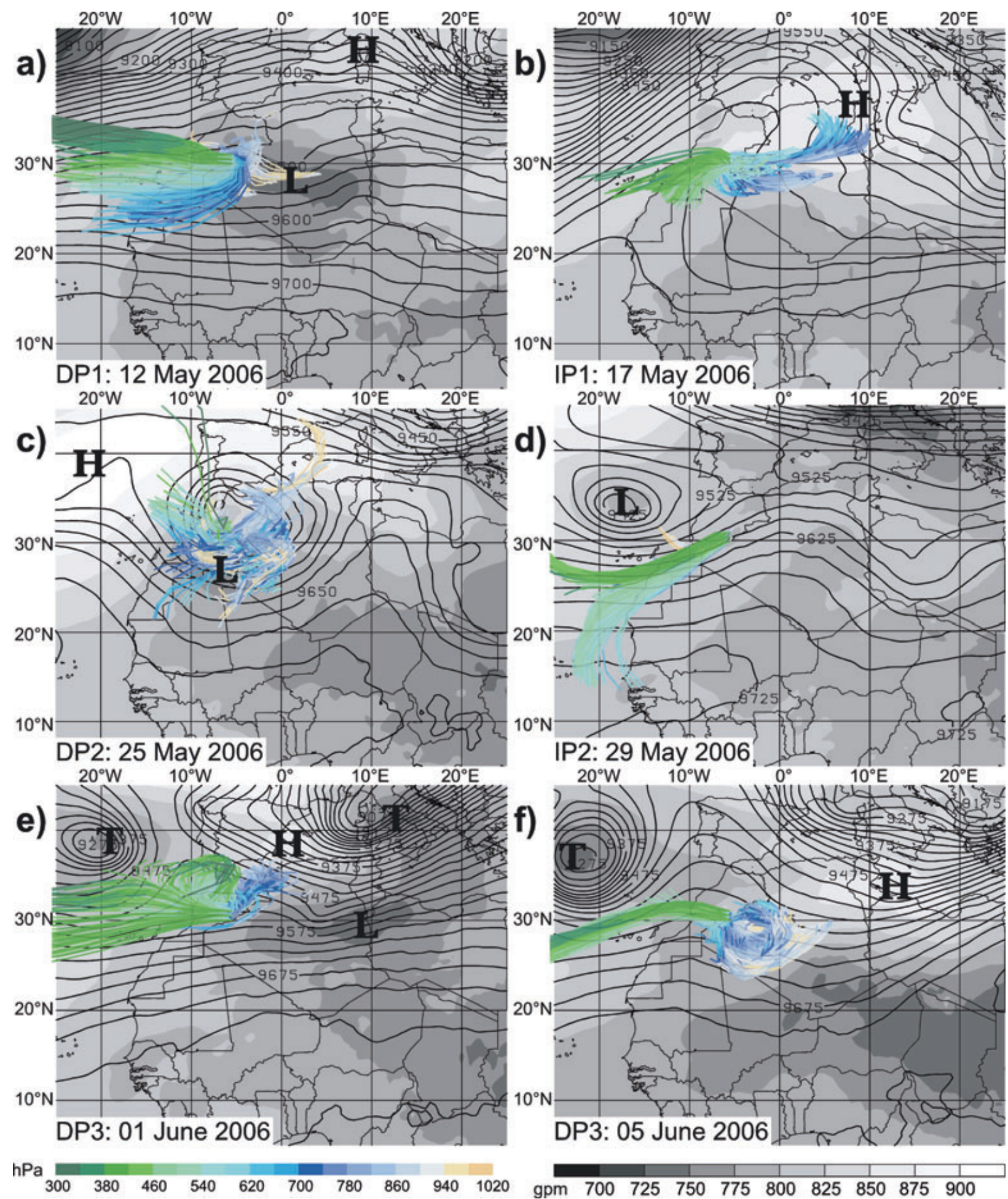

Fig. 3. Geopotential height at $300 \mathrm{hPa}$ (isohypses every $25 \mathrm{gpm}$ ) and at $925 \mathrm{hPa}$ (grey shading according to the scale at the bottom right), and 2-d backward trajectories for 1200 UTC on (a) 12 May, (b) 17 May, (c) 25 May, (d) 29 May, (e) 1 June and (f) 5 June 2006. Trajectories were started from each gridpoint within the 3-D box spanning $30.0^{\circ} \mathrm{N}-31.0^{\circ} \mathrm{N}, 7.0^{\circ} \mathrm{W}-5.5^{\circ} \mathrm{W}$ and surface- $400 \mathrm{hPa}$ (i.e. 12 gridpoints per level and ca. 30 levels) and run backwards in time for $48 \mathrm{~h}$. The trajectories are colour-coded with pressure according to the legend at the bottom left. ' $\mathrm{L}$ ' and ' $\mathrm{H}$ ' mark surface lows and highs, respectively. 


\subsection{Dust phase 2(22-27 May 2006) and intermediate phase 2 (28-30 May 2006)}

On 22 May an abrupt increase in AOT occurred at TNF (Fig. 2), the causes of which will be analysed in Section 5.3. This event was the start of the second dust phase (DP2) that lasted until 27 May. It exhibits the highest AOTs, lowest visibility and lowest downwelling irradiances during the entire campaign, very strong short-time fluctuations and at times large differences between the two measuring stations. The large-scale circulation was characterized by the passage of an upper-level short-wave and a lee cyclogenesis on 20-23 May (not shown), and the subsequent formation of a pronounced cut-off low over northwestern Africa on 24-27 May (Fig. 3c). The latter was associated with unsettled weather conditions in the entire region. Several precipitation events occurred at ORZ, and on 26 May rainfall was observed at TNF too. About $250 \mathrm{~km}$ ENE of ORZ flooding led to the death of six people. Strong winds of up to $15 \mathrm{~m} \mathrm{~s}^{-1}$ on 23-27 May caused blowing sand and strongly varying AOTs at TNF. Trajectory analysis reveals the inflow of Atlantic air masses on 23 and 24 May. AOT measurements at ORZ on 23 May show very small values, but are flagged by AERONET due to the presence of clouds. The visibility was $20 \mathrm{~km}$ on this day, consistent with a clean marine air mass (Fig. 2). For 25-27 May trajectories mostly reflect the cyclonic circulation associated with the cut-off low (Fig. 3c).

The period from 28 to 30 May is termed IP2. During this time the cut-off low retreated to the Atlantic north of the Canary Islands leaving a weak upper-level ridge over the SAMUM region (Fig. 3d). On 28 May (GD2) there was still a weak inflow of low-level dusty air from Algeria with AOTs around 0.4 (Fig. 2). This dust got mixed through the depths of the PBL in the course of the day as revealed by Figs. $4 \mathrm{~b}$ and $\mathrm{c}$ (discussed in more detail in Section 4). On 29 and 30 May inflow of clean air from the southwest at all levels caused AOTs as low as 0.05 (typical of a clean marine air mass), downwelling irradiances of up to $1.8 \mathrm{~W} \mathrm{~m}^{-2} \mathrm{~nm}^{-1}$ and a visibility of $>80 \mathrm{~km}$ at times (Fig. 2). The increase in AOT and decrease in visibility during the day at TNF might be related to local dust devil and dust plume activity (Ansmann et al., 2008b).

\subsection{Dust phase 3 (31 May-7 June 2006)}

The third dust phase (DP3) began with a slow increase in dustiness from 31 May to 3 June, when a maximum AOT of 1.1 and a visibility around $8 \mathrm{~km}$ was observed at TNF (Figs. 2a and b). Due to the presence of clouds no downwelling irradiance measurements are shown in Fig. 2c for the later parts of this day. After 3 June moderate dustiness with AOTs between 0.2 and 0.8 , and visibility between 10 and $25 \mathrm{~km}$ prevailed until the end of the campaign. A large upper-level trough over the central and eastern Mediterranean, a weak ridge close to the Iberian Peninsula and a cut-off low over the Atlantic dominated the upper-level circulation during DP3 (Figs. 3e and f). On 31 May and 1 June the cut-off low, which was previously located off the Moroccan coast (see Fig. 3d), moved across the Atlas and merged with the trough over the Mediterranean, accompanied by the shift of a lee cyclone from Morocco to Libya (marked ' $L$ ' in Fig. 3e). The dust mobilization associated with this development will be analysed in Section 5.1. The third golden day (GD3; 4 June 2006) was dominated by the advection of dusty air from this event into southern Morocco. After 2 June the upper ridge strengthened and surface pressure over northwestern Africa quickly rose. While southern Morocco was influenced by air masses from the north and west at the beginning of DP3 (Fig. $3 \mathrm{e})$, the strengthening of the low-level anticyclone led to the advection of dustier air masses from the east on 2-7 June (Fig. 3f). The synoptic evolution and air mass characteristics during DP3 are similar to DP1 and the beginning of IP1. During 31 May-4 June the evaporation of precipitation from deep convection over the Atlas generated density currents with strong gusts in the Saharan foothills that contributed to the observed dustiness at TNF (Knippertz et al., 2007).

\section{PBL characteristics}

The radiosonde and lidar observations at ORZ provide information on the vertical structure and diurnal cycle of the warm-season PBL in this semi-arid region. On many of the calm days, particularly during IP1 and IP2, the PBL showed a layer structure in the morning with two or more capping inversions and associated jumps in dew point, wind direction and dustiness as illustrated by the radiosonde at 1042 UTC on 28 May (i.e. GD2; black lines in Fig. 4a). Near the surface there is a shallow superadiabatic layer that is related to the intense solar heating during the morning hours. At $775 \mathrm{hPa}[\sim 2.3 \mathrm{~km}$ above sea level (asl), $\sim 1.2 \mathrm{~km}$ above ground level (agl)] there is a stable layer that exhibits a marked decrease in relative humidity $(\mathrm{RH})$ from $42 \%$ to $22 \%$, a decrease in dustiness and a wind shift from easterlies to southerlies (Figs. 4a and b). Between 635 ( $\sim \mathrm{km}$ asl, $\sim 2.9 \mathrm{~km} \mathrm{agl}$ ) and $600 \mathrm{hPa}$ the temperature is almost constant and $\mathrm{RH}$ decreases from $40 \%$ to $5 \%$. The upper boundary of the dust layer coincides with this capping inversion (Fig. 4b). The dry and clean free troposphere (FT) shows only weak backscattering. The two layers below $635 \mathrm{hPa}$ have a dry-adiabatic lapse rate and almost constant water vapour mixing ratios (MRs). The former layer is actively mixed due to heating of the underlying surface and is therefore called the mixed layer (ML). The latter is the upper-part of the deep convective ML of the previous day that was decoupled from the surface by radiative cooling during the night. This layer is called a residual mixed layer (RML; Warner, 2004, chapter 2). Such a PBL structure has previously been noted by Parker et al. (2005) and Flamant et al. (2007) for the southern Sahara and the Sahel. The lidar signals show a continuous growth of the ML into the RML with first convective dust plumes breaking through the lid at $2.2 \mathrm{~km}$ asl around 1100 
a)
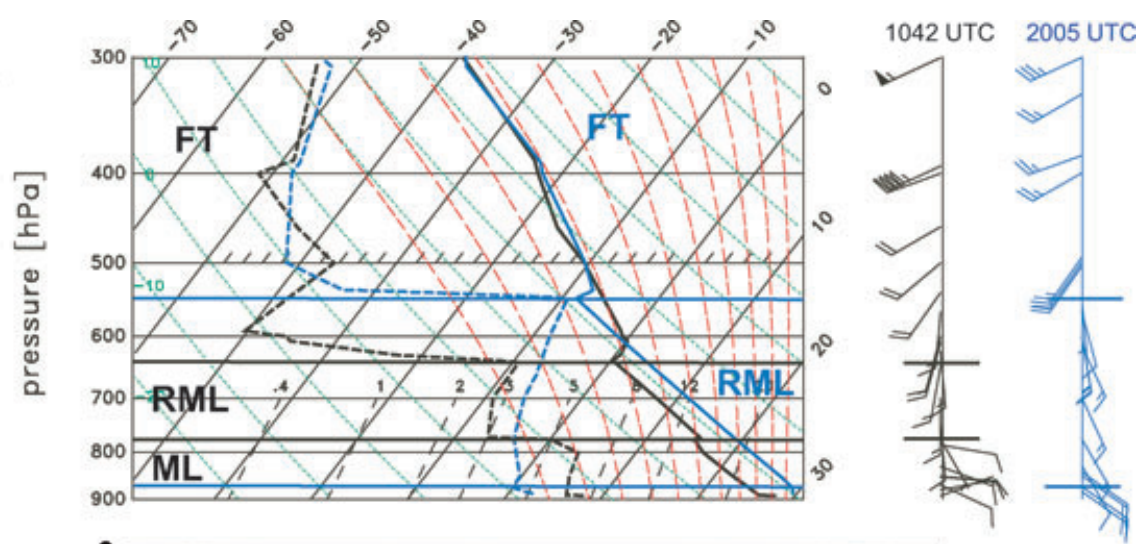

b)

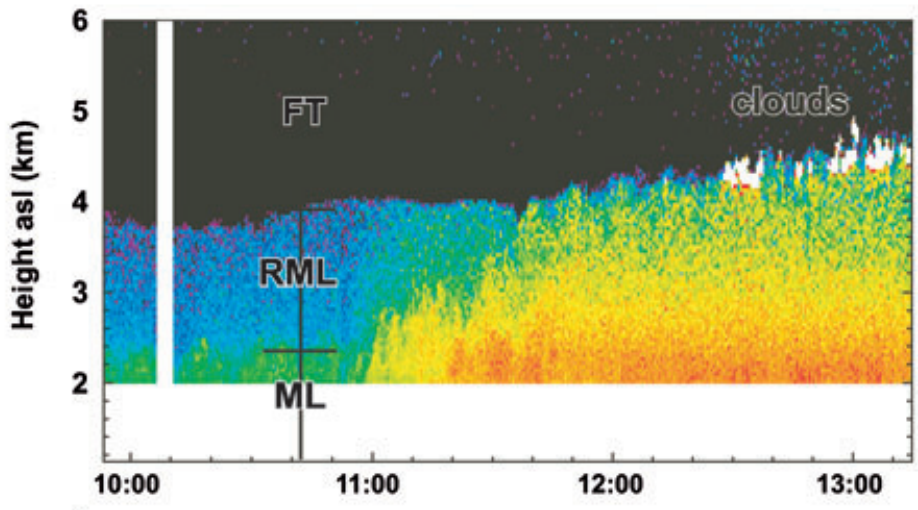

21.0

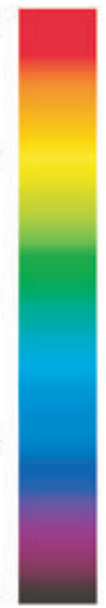

LOGARITHM

OF DATA

Fig. 4. Radiosonde and lidar profiles at ORZ on 28 May 2006. (a) Standard $T-\log p$ diagram showing temperature, dew point and wind at 1042 UTC (black) and 2005 UTC (blue). Range-corrected attenuated backscattering at 1064-nm at (b) 0953-1315 UTC and (c) 1943-2218 UTC. The radiosonde launches with the vertical positions of capping inversions and layers (FT, free troposphere; RML, residual mixed layer; ML, mixed layer), and clouds are marked in (b) and (c).

UTC. This leads to a homogenization of the dust concentrations and a rising of the ML top to $>4 \mathrm{~km}$ asl at approximately 1200 UTC (Fig. 4b). The vertical mixing increases RH in the upper part of the PBL and leads to the formation of shallow cumuli by 1230 UTC. The last two PBL cumuli of the day are observed by the lidar as high as $5.4 \mathrm{~km}$ asl shortly after sunset at 1924 UTC (Fig. 4c). Despite their elevation these clouds are not classical altocumuli, but generated by deep PBL mixing (see Ansmann et al. (2008a) for more discussion on PBL clouds during SAMUM).
The second radiosonde was released at 2005 UTC (41 min after sunset), when radiative cooling had led to a weak inversion near the surface (Fig. 4a). Above the shallow nocturnal boundary layer, the vertical mixing observed during the day had led to a deep almost dry-adiabatic RML, with a sharp capping inversion at $5.3 \mathrm{~km}$ asl $(540 \mathrm{hPa})$. At this height a temperature increase of $0.7^{\circ} \mathrm{C}$ within $20 \mathrm{~m}$ was recorded by the radiosonde. The inversion is most likely dynamically generated by largescale subsidence, since dust radiative effects tend to warm the dust layer (Miller and Tegen, 1999). MRs are almost constant in 
the upper part of the RML and increase somewhat towards the surface, which points to moisture sources there. RH increases from $16 \%$ at the ground to more than $90 \%$ at the top of the RML. Above that, RH sharply decreases to $10 \%$ within only about $200 \mathrm{~m}$. There is a distinct wind shift from southeasterlies observed in the RML to southwesterlies or westerlies in the free FT, which is also reflected in some of the trajectories discussed in Section 3 (see Figs. $3 b$ and f). The lidar profile shows rather constant dust concentration throughout the entire RML (recall that the attenuated signal decreases with height) and a slow sinking of the dust layer top to $4.9 \mathrm{~km}$ asl until 2220 UTC (Fig. 4c). The reason for the unusual weakening of the lidar signal in the uppermost part of the dust layer after 2100 UTC is unclear. A possible explanation is horizontal advection of less dusty air from the sides together with a diminishing mixing from below.

Many other days during SAMUM 2006 had a similar PBL evolution and at times capping inversions as high as $500 \mathrm{hPa}$ were observed. First indications of dry convective plumes were usually observed between 1000 and 1100 UTC, deep mixing and formation of PBL clouds often occurred before 1300 UTC. However, during the wet and windy DP2 the PBL structure was usually more complicated (not shown). Generally, the time needed for the ML to consume the RML appears to depend on differential temperature advection, subsidence in the upper layers, dust content, cloud cover and soil moisture (Carson, 1973).

Figures $4 \mathrm{a}$ and $\mathrm{b}$ show that the morning ML is moister and dustier than the RML. Considering the different wind speeds and directions in the two layers differential advection during the night is a likely cause. An illustrative example of this phenomenon and the subsequent mixing occurred during the morning hours of GD3 4 June. Lidar signals between 0930 and 1030 UTC show a confined dust maximum around $2.7 \mathrm{~km}$ asl surrounded by less dusty layers aloft and below (Fig. 5; see also fig. $4 \mathrm{f}$ in Esselborn et al., 2008). Until mid-day the dust gets mixed and shallow clouds form at the top of the ML. The dust maximum may be related to transport of air from a dustier location to ORZ by a nocturnal low-level jet associated with reduced eddy viscosity above the surface layer (Stensrud, 1996). However, by the time of the radiosonde ascent at 1039 UTC there is only a moderate southerly wind maximum in this layer (Fig. 5). Trajectory analysis reveals that the dusty air is advected from southerly directions, while the air at lower levels reaches southern Morocco from the southeast (not shown).

Around the time of the breaking of the internal capping inversion, downward mixing can produce distinct jumps in weather conditions at the surface (Washington and Todd, 2005). On 4 June for example visibility at ORZ decreases from 10 to 8 $\mathrm{km}$ between 06 and 09 UTC (Fig. 2b) due to downward mixing of the elevated dust maximum seen in Fig. 5. Other examples are the visibility changes at TNF in the morning hours of 18 and 23 May, and 2 June 2006 (Fig. 2b). The characteristic evolution of the PBL has important implications for the dust transport into the region and the interpretation of dust samples taken during SAMUM. The strong daytime PBL mixing implies that a sample taken at any height within the lowest $\sim 4$ $\mathrm{km}$ of the atmosphere can in principle originate from anywhere within the entire layer. Therefore, a source region identification using trajectories should comprise the entire depth of the PBL as in Sodemann et al. (2006). Strictly speaking, however, such a trajectory analysis only accounts for the mixing that occurred near the observation site, but not for the mixing during preceding days. During the night, vertical mixing is usually so weak that horizontal advection becomes the dominating influence on air mass characteristics. The latter is usually well represented by trajectories calculated from ECMWF analyses, even though the complex multilayer structure seen in the radiosondes is not always well reproduced (not shown).

\section{Dust mobilization and transport for three selected days}

In this section we will investigate the processes of dust emission and transport for three selected dust days during SAMUM 2006. The analyses of the first two cases consist of three steps:
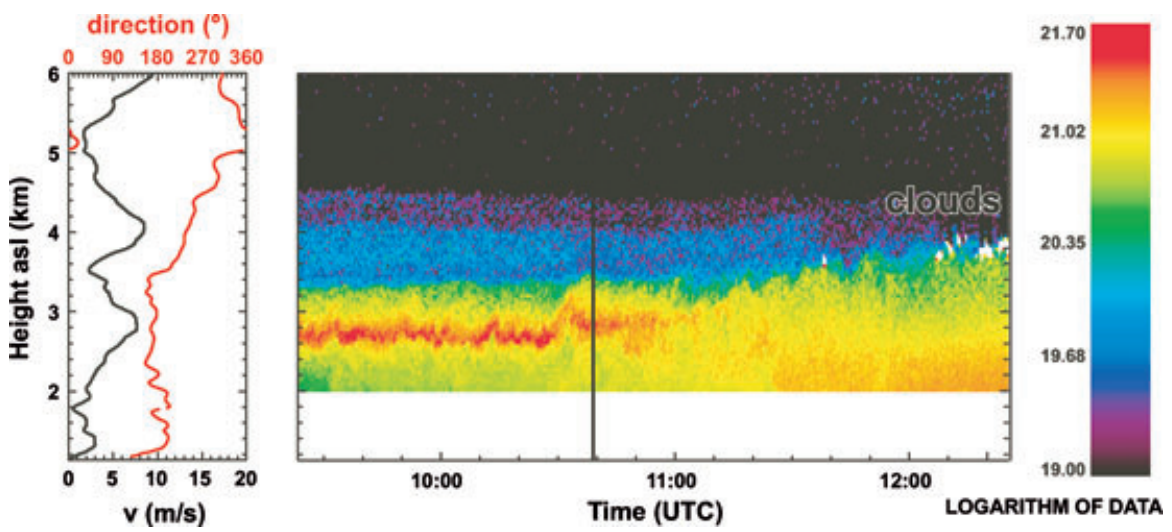

Fig. 5. Range-corrected attenuated backscattering at 1064-nm at ORZ at 0924-1225 UTC 4 June 2006 together with wind measurements by radiosonde at $1039 \mathrm{UTC}$. 


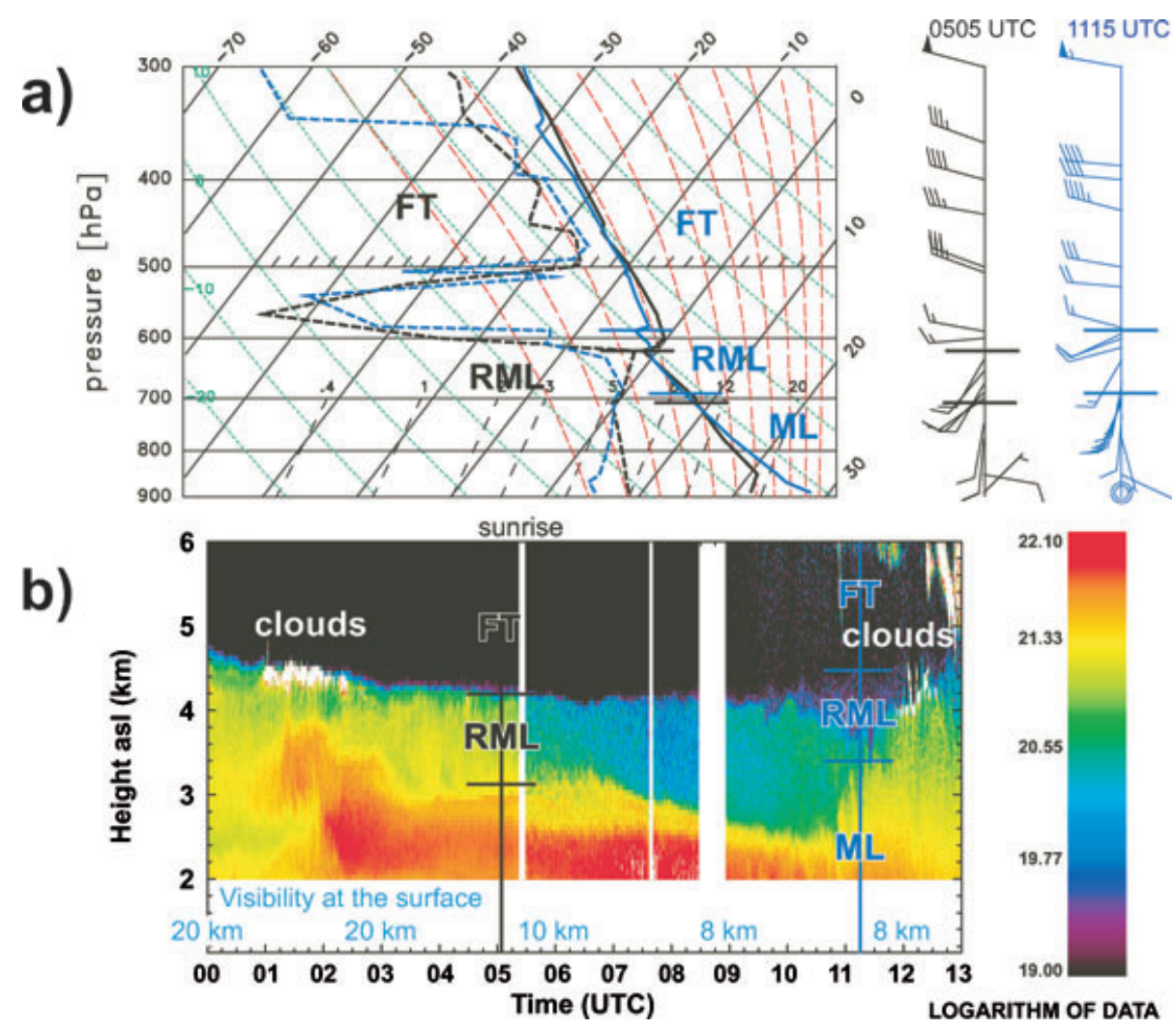

Fig. 6. Case I: As Fig. 4 but for the radiosonde ascents at 0505 UTC (black) and 1115 UTC (blue), and range-corrected attenuated backscattering at 1064-nm at 0000-1300 UTC on 3 June 2006. Horizontal visibility observations at ORZ are given in blue.

characterization of the dust layer over the study region; source region identification with backward trajectories and examination of dust mobilization over the source regions. The investigation of the third case, which is strongly influenced by moist convective dynamics, mainly relies on satellite information.

\subsection{Case I: 3 June 2006}

5.1.1. Vertical structure of the dust layer. As discussed in Section 3, 3 June is the day with maximum AOTs (up to 1.1) and minimum visibility at TNF during DP3 (Fig. 2). Aerosol optical thickness values at ORZ are substantially lower and reach about 0.5 only. Lidar observations from ORZ show the arrival of a dusty air mass around 0200 UTC on this day (Fig. 6b). The reason why the lidar signal descends during the first few hours is unclear. At the time of the first radiosonde launch at 0505 UTC a layered structure is clearly discernable. Low levels exhibit easterly winds and a stable stratification that is most likely related to radiative cooling (Fig. 6a). Above this layer to an altitude of $\sim 3.1 \mathrm{~km}$ asl (705 hPa) is an optically thick dust layer with southerly winds. This layer is weakly stable and not well mixed as shown by a decrease in MR with height from 8 to $5.3 \mathrm{~g} \mathrm{~kg}^{-1}$. A sharp capping inversion around $4.2 \mathrm{~km}$ asl $(616 \mathrm{hPa})$ with a temperature increase of $1^{\circ} \mathrm{C}$ in $32 \mathrm{~m}$ separates the clean FT with westerly winds from the fairly well mixed, but only moderately dusty RML with southwesterly winds (Fig. 6). The vertical structure of the dust layer is consistent with lidar observations from a flight with the DLR Falcon in the morning of 3 June (see figs. 3 and 4 in Esselborn et al., 2008, and fig. 4 in Petzold et al., 2008). At the surface horizontal visibility is comparably high (Fig. 6b; see also measurements at TNF in $2 b$ ).

Between sunrise at 0527 UTC and about 1040 UTC solar heating triggers shallow dry convection that erodes the nocturnal inversion and mixes dust from mid-levels to the surface as indicated by decreasing horizontal visibility (Figs. 6b and 2b). At the time of the second radiosonde at 1115 UTC the atmosphere is unstable near the surface indicating large solar heating of the ground (Fig. 6a). Above that an almost dry-adiabatic ML with constant MR begins to grow into the RML as shown by the dusty convective plumes in the lidar image (Fig. 6b). Winds change from southerlies near the surface to westerlies in the FT (Fig. 6a). The ML continues to deepen and at around 1145 UTC first cumulus clouds form around $4 \mathrm{~km}$ asl $(630 \mathrm{hPa})$, where a weak inversion is discernable in Fig. 6a. At 1230 UTC the clouds break through this lid and reach the base of the FT around $4.5 \mathrm{~km}$ asl $(590 \mathrm{hPa})$. At this time dry convection mixes dust throughout the entire depth of the ML (Fig. 6b). 


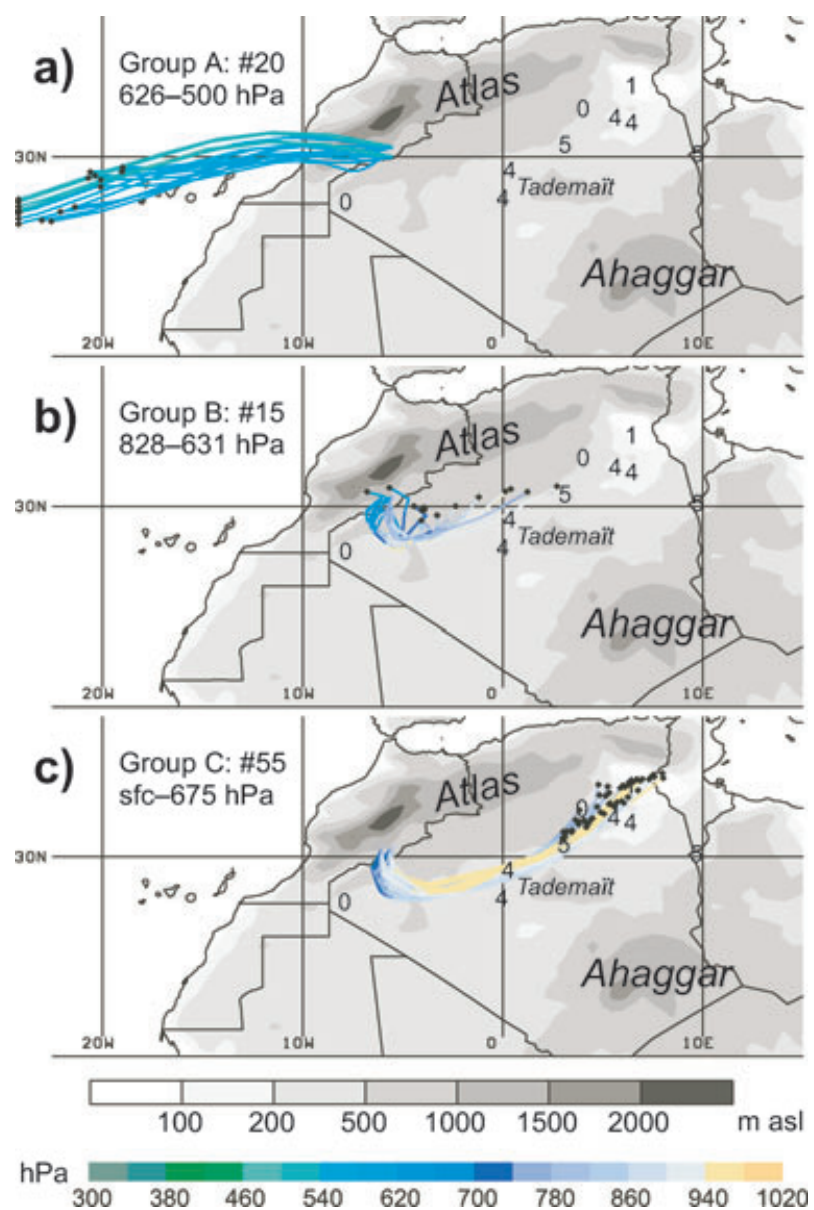

Fig. 7. Case I: Two-day backward trajectories started from the 3-D box $30.0^{\circ} \mathrm{N}-30.5^{\circ} \mathrm{N}, 6.0^{\circ} \mathrm{W}-5.5^{\circ} \mathrm{W}$, surface- $-500 \mathrm{hPa}$ at $1200 \mathrm{UTC} 3$ June 2006. The 90 trajectories were subjectively assigned to three groups with similar behaviour. The trajectories are colour-coded with pressure (in $\mathrm{hPa}$ ) according to the legend at the bottom. Trajectory origins are marked with black circles. Grey shading indicates the elevation of the ECMWF topography at $0.5^{\circ}$ horizontal resolution. The number of reports of 'dust or sand raised by the wind' at synoptic stations near the trajectory tracks during the first day (eight synoptic hours from 1200 UTC 1 June to 0900 UTC 2 June 2006) are given as numbers. For information on the used stations, see Table 1.

5.1.2 Trajectory analysis. To identify the causes for the increased dustiness on 2 and 3 June 48-h backward trajectories were calculated from the four gridpoints surrounding the measuring site at $\mathrm{TNF}\left(30.0^{\circ} \mathrm{N}-30.5^{\circ} \mathrm{N}, 6.0^{\circ} \mathrm{W}-5.5^{\circ} \mathrm{W}\right)$ at each ECMWF (unevenly spaced) model level between the surface and $500 \mathrm{hPa}$. Starting time is 1200 UTC 3 June, which is close to the maximum AOT at TNF. In total 90 trajectories were assigned to three groups representing the three-layer structure described in Section 5.1.1: (A) Between 626 and $500 \mathrm{hPa}$ we obtain $20 \mathrm{FT}$ trajectories that originate from the eastern Atlantic at $25^{\circ} \mathrm{N}-30^{\circ} \mathrm{N}$, $32^{\circ} \mathrm{W}-19^{\circ} \mathrm{W}$ and slightly subside on their way to northwestern Africa (Fig. 7a). (B) In the upper part of the PBL between 828 and $631 \mathrm{hPa}, 15$ trajectories reach the study region from origins within $29^{\circ} \mathrm{N}-31^{\circ} \mathrm{N}, 7^{\circ} \mathrm{W}-3^{\circ} \mathrm{E}$ (Fig. 7b). This group does not show a very coherent behaviour with both strongly subsiding and moderately rising trajectories. The strong wind shift at the impervious inversion at the top of the PBL results in a clear distinction between Groups A and B. (C) Below $675 \mathrm{hPa}$ there is a coherent airstream consisting of 55 trajectories that originate from the northeastern and central Algerian lowlands around $30.9^{\circ} \mathrm{N}-34.2^{\circ} \mathrm{N}, 3^{\circ} \mathrm{E}-8^{\circ} \mathrm{E}$ and then follow the topographic channel between the foothills of the Atlas and the Tademait Plateau (Fig. 7c). Synoptic stations along the track frequently reported dust mobilization on 1 and 2 June. Over the source region the trajectories stay within the layer between 988 and $736 \mathrm{hPa}$, mostly on quasi-horizontal tracks. Interestingly, trajectories closer to the surface have origins farther away, which points to a decrease of wind speed with height over the source region. The fact that Groups B and C overlap vertically over southern Morocco reflects the vertical mixing between the two airstreams. A similar analysis conducted for the four gridpoints surrounding ORZ shows similar results, but with a larger fraction of trajectories from westerly directions, which explains the lower AOTs over this site (Fig. 2a). Differences to trajectories started at 0600 UTC were generally rather small (not shown).

5.1.3 Dust mobilization. In the following we will discuss possible mechanisms of dust emissions for the two PBL trajectory groups. Group B is of local origin and not associated with high wind speeds. Most trajectories are slowly descending from the Atlas Mountains into the foothills. During the night from 31 May to 1 June, immediately before the endpoints of the trajectories (i.e. 1200 UTC 1 June), moist convection over the Atlas generated density currents associated with strong winds of up to $19 \mathrm{~m} \mathrm{~s}^{-1}$ and dust mobilization (Knippertz et al., 2007). By the next morning remnants of the cold and dusty air are still visible in IR satellite imagery over western Algeria (Fig. 8a). Dust emission most likely occurred from wadis or smaller topographic depressions in the foothills of the Jebel Saghro and the Sahara Atlas (see Fig. 1) rather than from extended source areas, which could explain the comparably low dust content in this air mass (Fig. 6b). It appears that the high wind speeds associated with evaporationally driven density currents are not well represented in operational ECMWF analyses over the data-sparse Sahara.

The trajectories of Group $\mathrm{C}$ were involved in a significant dust storm over Algeria associated with a cold surge from the Mediterranean Sea. The development of this surge is related to an upper-level cut-off low that moves from the Atlantic across the Atlas on 30-31 May and then merges with a large upperlevel trough over the central Mediterranean on 1 June 2006 (see Section 3; Fig. 3e). At 0600 UTC on this day the strong low-level northerly flow of cold air on the western side of the upper-trough is blocked by the Algerian Atlas (Fig. 9). In the lee of the mountains a cyclone forms as shown by the geopotential height minimum at $925 \mathrm{hPa}$. This evolution leads to strong 

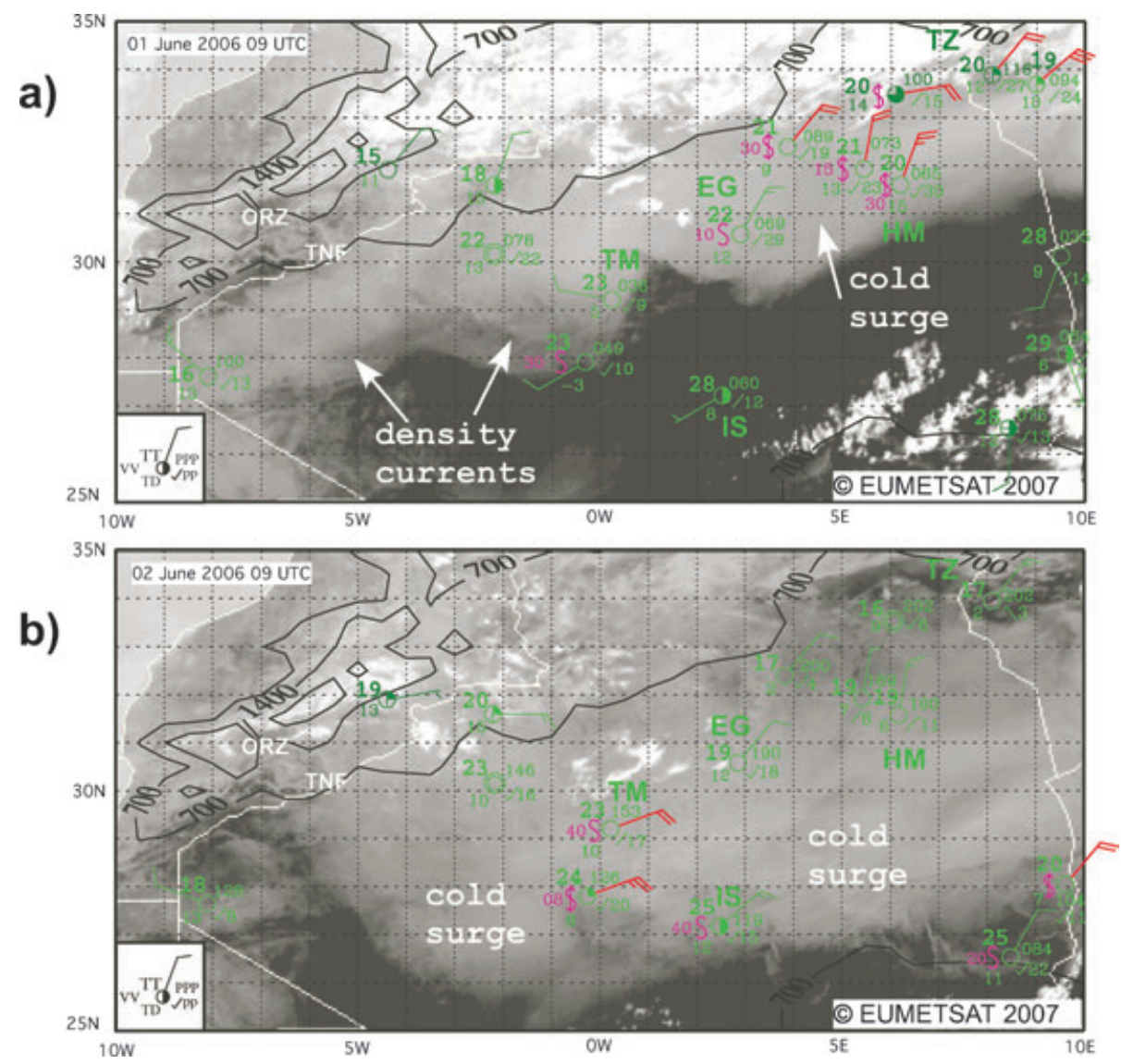

Fig. 8. Case I: Meteosat Second Generation IR image at 0900 UTC with selected station observations at 0600 UTC for (a) 1 June and (b) 2 June 2006. The synoptic observations are depicted in a reduced WMO station model (WMO, 1995; see legend) showing 2-m temperature (TT) and dew point (TD) in ${ }^{\circ} \mathrm{C}$ (numbers on the left), pressure reduced to mean sea level (PPP) and 3-h pressure tendency (pp) in 1/10 hPa (numbers on the right-hand side), cloud coverage in octas (circles), and wind speed and direction (half barb, $5 \mathrm{kn}$; full barb, $10 \mathrm{kn}$; in red if $\geq 20 \mathrm{kn} ; 1 \mathrm{kn}=0.54 \mathrm{~m}$ $\mathrm{s}^{-1}$ ). Magenta numbers give visibility (VV) below $5 \mathrm{~km}$ (in $100 \mathrm{~m}$ intervals). Magenta symbols indicate reports of "widespread dust in suspension in the air, not raised by wind' (S) and 'dust or sand raised by the wind' (\$). European Centre for Medium-Range Weather Forecasts topography isohypses of 700, 1400 and $2100 \mathrm{~m}$ are plotted in black. Some of the synoptic stations mentioned in the text are marked (for abbreviations, see Table 1).

temperature and pressure gradients near the eastern tip of the Atlas. Early on 1 June the cold air begins to surge across Tunisia into northeastern Algeria with wind speeds of more than $20 \mathrm{~m} \mathrm{~s}^{-1}$ at $925 \mathrm{hPa}$ (Fig. 9). Surface observations at 0600 UTC indicate strong northeasterly winds, low visibility and dust mobilization over western Tunisia and the lowlands in northeastern Algeria (Fig. 8a). At this time temperature and dew point contrasts between In Salah and Hassi Messaoud are 8 and $7{ }^{\circ} \mathrm{C}$, respectively (Fig. 8a). The IR image at 0900 UTC also shows the contrast between the dusty cold surge and the less dusty, hot desert farther to the south (dark in the IR image). Close to the leading edge of the cold air there is a fairly large pressure gradient and a distinct shift in wind direction between Timimoun and El Golea (Fig. 8a). All stations in the northeast show positive pressure tendencies of up to $3 \mathrm{hPa} 3 \mathrm{~h}^{-1}$ (Fig. 8a).

The vigour of the cold surge is illustrated by observations from the northeast Algerian station Hassi Messaoud that records 24-h changes in temperature and station pressure of $-13^{\circ} \mathrm{C}$ and $+16 \mathrm{hPa}$, respectively (Figs. 10a and b), and 10-m winds of up to $15 \mathrm{~m} \mathrm{~s}^{-1}$ (not shown). These values are typical of the cold front passage of a Sharav/Khamsin cyclone (El Fandy, 1940; Alpert and Ziv, 1989). Mid-day radiosonde ascents from the western Tunisian station Touzeur show that the cooling and the change in wind direction associated with the cold surge are confined to levels below $600 \mathrm{hPa}$ (Fig. 10c). Such a shallow cold front is typical of Sharav cyclones (Alpert and Ziv, 1989). The strong temperature and pressure gradients at the surface during the cold surge explain the decrease of wind speed with height reflected in the trajectory analysis (see Section 5.1.2). In the course of 1 June more dust mobilization is observed along the track of Group C (Fig. 7). In the morning hours of 2 June the cold air surges farther into the Sahara, but wind speeds are lower and observations of dust mobilization and low visibility are less frequent (Fig. 8b). In the evening hours of 2 June another density current was observed 


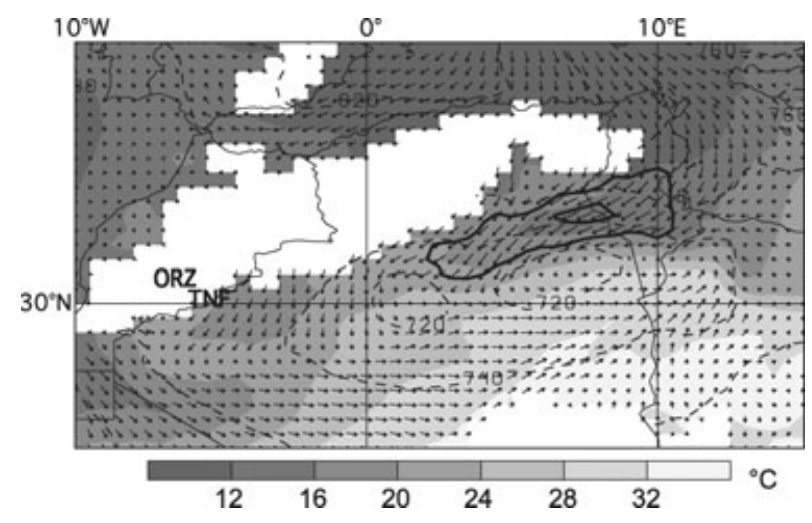

Fig. 9. Case I: Wind vectors, geopotential height (contoured every 20 gpm) and temperature (grey shading) at $925 \mathrm{hPa}$ for 0600 UTC 1 June 2006. The thick black lines indicate the 15 and $20 \mathrm{~m} \mathrm{~s}^{-1}$ isotachs. Regions where the ECMWF topography lies above $925 \mathrm{hPa}$ are white. The SAMUM stations ORZ and TNF are marked.

over the SAMUM region (Knippertz et al., 2007). Again the associated wind maxima are poorly represented in ECMWF trajectories, but the emitted dust might have contributed to the increase in AOT on 3 June (Fig. 2).

In conclusion, the main dust sources for this event appear to be located in the northeastern and central Algerian lowlands and adjacent Tunisia. The dust mobilization is associated with a cold surge from the Mediterranean. Being characterized by synoptic-scale, predominantly dry dynamics this event is fairly well reproduced by the LM-MUSCAT-DES with $20 \mathrm{~km}$ horizontal resolution (Heinold et al., 2008). Dust samples taken from within the ML over TNF in the morning of 3 June have unusually high calcium contents (figs. 17 and 18 in Kandler et al., 2008) and high Angström exponents of absorption (table 1 in Petzold et al., 2008), which point to mobilization from the salt pans in the Chott areas of Tunisia and northeastern Algeria (Group C in Fig. 7). In contrast, samples taken at $3.8 \mathrm{~km}$ asl, that is from within the RML (Group B in Fig. 7), show mineralogical and optical characteristics more typical of local dust sources, consistent with a connection to density currents in the Atlas. On 4 June (GD3) samples from different heights show more homogeneous calcium contents (K. Kandler, personal communication, 2007) and optical properties (Petzold et al., 2008), pointing to deep vertical mixing of the dust contained in Group C (see Fig. 5).

\subsection{Case II: 14 May 2006}

5.2.1 Vertical structure of the dust layer. As discussed in Section 3, DP1 is characterized by a steady increase of AOT from 12 to 14 May with small differences between TNF and ORZ (Fig. 2a). Visibility at ORZ drops from 20 to $6 \mathrm{~km}$ between 0300 and 0600 UTC on 13 May and then stays between 6 and $8 \mathrm{~km}$ on 14 and 15 May (Fig. 2b). The arrival of the dusty air on 13 May is accompanied by a shift from weak northwesterly winds to easterlies at $10 \mathrm{~m} \mathrm{~s}^{-1}$ and a 24-h increase in 850-hPa geopotential height by $51 \mathrm{gpm}$ (not shown). The strong winds appear to break the nocturnal surface inversion, resulting in a warming at the surface before sunrise (see Knippertz et al., 2007). The TNF station measured winds of up to $12 \mathrm{~m}$ $\mathrm{s}^{-1}$ on this day. The radiosonde ascent at 1042 UTC on 13 May (Fig. 11a) shows the typical layered structure with a dry FT with westerlies, a sharp capping inversion at $601 \mathrm{hPa}(4.4 \mathrm{~km}$ asl), a moderately well-mixed RML with southeasterlies in this case, an internal capping inversion at $725 \mathrm{hPa}(\sim 2.9 \mathrm{~km}$ asl $)$, an $\mathrm{ML}$ with strong easterlies and finally a shallow superadiabatic layer at the surface. The much lower potential temperature and higher MR in the ML as compared to the RML (5.4 vs. $1.9 \mathrm{~g} \mathrm{~kg}^{-1}$ ) indicate the advection of a moist and cool air mass from the east. By 14 May a homogenization of this air mass has taken place. The radiosonde launched at 1035 UTC and the lidar signals show a $\sim 3.5$-km deep layer with almost constant potential temperature, MR $\left(\sim 2.4 \mathrm{~g} \mathrm{~kg}^{-1}\right)$, dust content (note the attenuation effect), and wind speed and direction under a sharp capping inversion at 588 hPa (Fig. 11). A clear distinction between an ML and a RML is not possible on this day. The lidar signal indicates strong dry convective activity, which pushes the top of the dust layer from 4.8 to $5.2 \mathrm{~km}$ asl during the period shown in Fig. $11 \mathrm{~b}$.

5.2.2 Trajectory analysis. The 90 back-trajectories started from the study region at 1200 UTC on 14 May, close to the peak of the AOT curve (Fig. 2a), can be partitioned into three groups similar to Case I (see Fig. 7). Between 566 and 501 hPa there are 12 slightly subsiding FT trajectories with eastward tracks (Fig. 12a). In the layer below (627-580 hPa) we obtain seven trajectories with origins over Algeria and Mali between $0.9^{\circ} \mathrm{W}$ and $4.5^{\circ} \mathrm{W}$ (Fig. 12b) that are representative for the uppermost part of the PBL (Fig. 11a). The main bulk of the trajectories, in total 71, track across southern Tunisia and then through the topographic channel between the foothills of the Atlas and the Tademait Plateau to southern Morocco, where they arrive at levels below $616 \mathrm{hPa}$ (Fig. 12c). There is a general tendency for the northern trajectories in Group $\mathrm{C}$ to be faster and lower. Dust mobilization is frequently observed along the trajectory track east of the Greenwich Meridian (numbers in Fig. 12). The dominance of Group C is consistent with the deep ML in Fig. 11.

5.2.3 Dust mobilization. As described in Section 3, the synoptic situation around 12 May is characterized by an upper-level short-wave moving from the Atlantic into Algeria and a cyclone in the lee of the Atlas (Fig. 3a). At the same time a surface high is located over the Central Mediterranean, leading to a strong pressure gradient across Tunisia and eastern Algeria (Fig. 3a) and to the advection of relatively cool air. The IR satellite image at 1800 UTC 12 May shows that deep moist convection has developed over the Atlas Mountains and at the eastern side of the upper-disturbance over eastern Algeria (Fig. 13a). There are some reports of 'dry' thunderstorms, but no precipitation was 

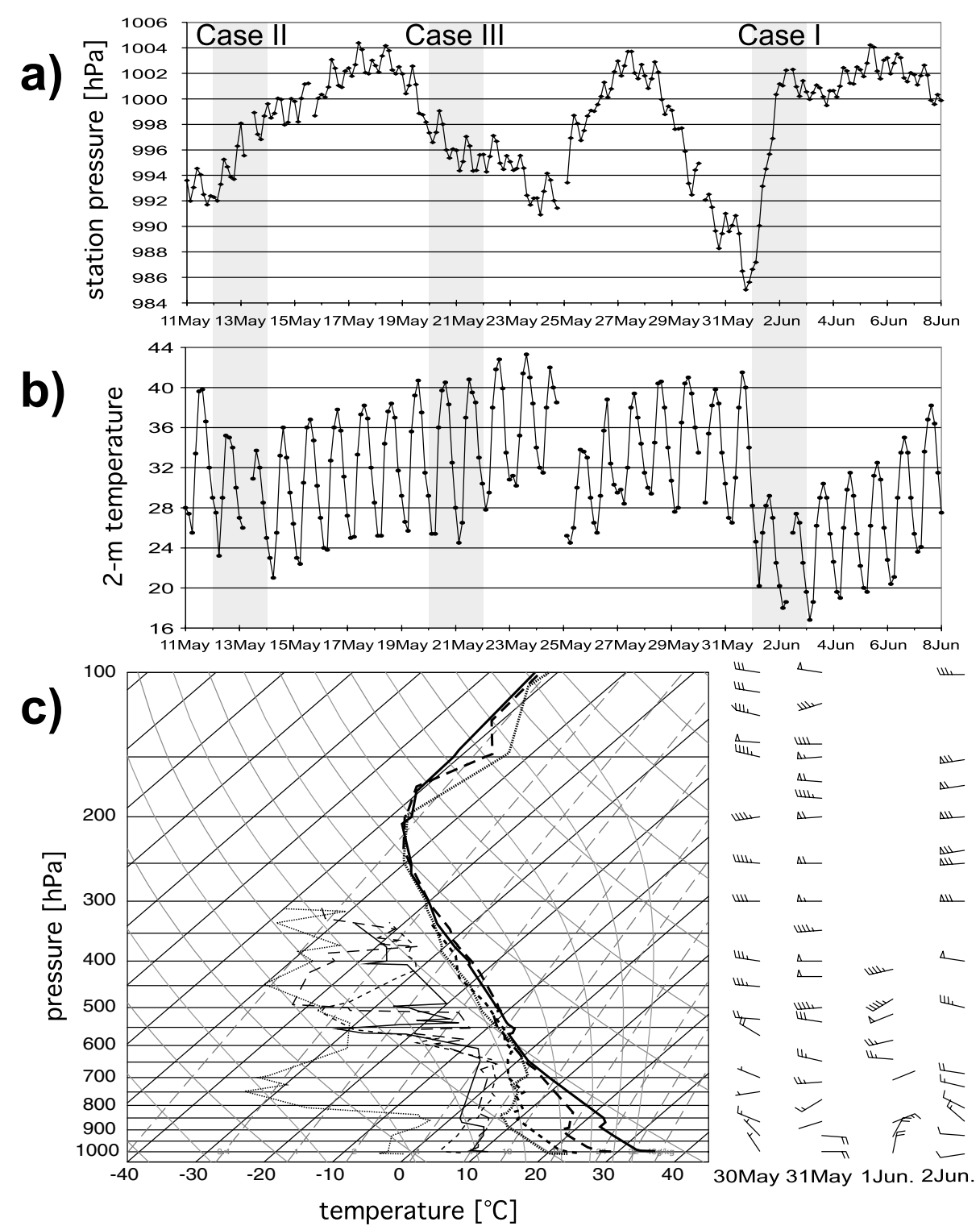

Fig. 10. Time-series from 11 May to 8 June 2006 of (a) station pressure and (b) 2-m temperature at Hassi Messaoud (Algeria, $\left.31.67^{\circ} \mathrm{N}, 6.15^{\circ} \mathrm{E}\right)$. The cases analysed in Section 5 are marked with grey shading. (c) Case III: 1200 UTC radiosonde profiles of temperature (thick lines), dew point (thin lines) and wind (barbs) at Touzeur (Tunisia, $33.92^{\circ} \mathrm{N}, 8.10^{\circ} \mathrm{E}$ ) for 30 May (solid), 31 May (long dashes), 1 June (short dashes) and 2 June (dots).

observed at the ground except for high-altitude stations in the Atlas. This suggests that evaporation and cloudiness strengthen the temperature gradient between the hot central Algerian Sahara with temperatures of up to $41^{\circ} \mathrm{C}$ and the northeast with temperatures between 28 and $34{ }^{\circ} \mathrm{C}$ (Fig. 13a). In the latter region 24-h temperature decreases of up to $6 \mathrm{~K}$ are observed (e.g. $4.8 \mathrm{~K}$ at Hassi Messaoud; see Fig. 10b). The temperature gradient is reflected in a sharp front in the IR signal running from the eastern High Atlas southeastward to the Great Eastern Erg in Algeria (see Fig. 1). Across this front there is a strong contrast in pressure between Timimoun and In Salah (1004.1 $\mathrm{hPa})$ on the warm side, and El Golea (1008.8 hPa) and Ghardaia
$(1014.5 \mathrm{hPa})$ on the cold side. The fact that the wind at stations to the northeast has a large component parallel to the pressure gradient points to a partly unbalanced flow driven by density differences. Wind speeds on the cold side reach $19 \mathrm{~m} \mathrm{~s}^{-1}$ and dust mobilization is observed throughout most of the day at $\mathrm{El}$ Oued, Hassi Messaoud, Ouargla and El Golea (Figs. 13a and 12). Visibility drops to $1-2 \mathrm{~km}$ at these stations during the afternoon and evening. Twenty-hour pressure increases range from 5 to $7 \mathrm{hPa}$ (e.g. Fig. 10a).

By 2100 UTC the front has passed Timimoun accompanied by a sudden shift to easterlies at $16 \mathrm{~m} \mathrm{~s}^{-1}$, dust mobilization and a visibility of $2 \mathrm{~km}$. By 0000 UTC 13 May the front has reached 


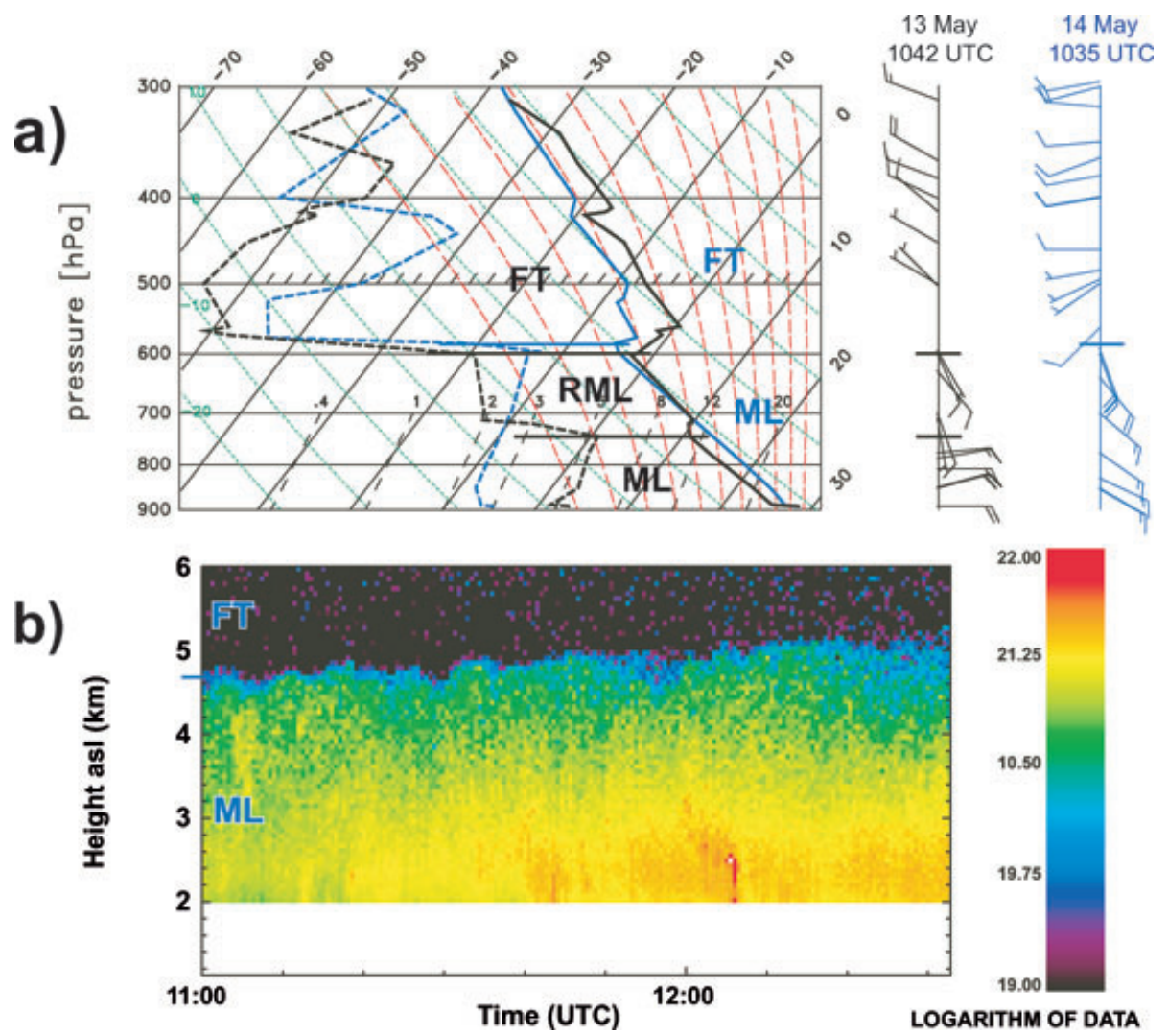

Fig. 11. Case II: As Fig. 4 but for the radiosonde ascents at 1042 UTC on 13 May 2006 (black) and at 1035 UTC on 14 May 2006 (blue) and range-corrected attenuated backscattering at 1064-nm at 1100-1232 UTC on 14 May 2006.

Adrar and causes equally dramatic weather conditions with visibility going down to $800 \mathrm{~m}$ in the early morning. The northern part of this front passes through the southern foothills of the High Atlas as indicated by the observations at ORZ and TNF described above (see also Knippertz et al., 2007). By the morning of 13 May the cold and dusty air has spread further, accompanied by strong winds and low visibility at Adrar, Timimoun and In Salah, while dust storms over northeastern Algeria weaken (Fig. 13b). The advection of the dusty air mass into southern Morocco eventually causes the observed increase in AOT on 14 May.

The presented results show some similarities to Case I. In both situations an upper-level short-wave passes over northern Africa accompanied by a surface cyclogenesis and a subsequent cold surge from the Mediterranean Sea into the lowlands between western Tunisian and central Algeria, where the main dust sources are located. However, for Case I strong cold advection from the mid-latitudes plays an important role, while evaporational cooling of convective precipitation supports the surge during Case II. As in Case I, the LM-MUSCAT-DES satisfactorily reproduces basic features of the event, although simulated AOTs on 13 and 14 May suffer from the presence of dust spuriously emitted during previous days (B. Heinold, personal communi- cation, 2007). Again, dust samples from TNF show enhanced calcium contents with respect to the rest of the campaign (fig. 17 in Kandler et al., 2008). Dust from Case II was transported to the Canary Islands and into southwestern Europe in association with the formation of an upper ridge (see Fig. 3b). It was detected during the DLR Falcon flight from Faro to Casablanca on 18 May (Weinzierl et al., 2008) and by EARLINET stations across Europe (D. Müller, personal communication, 2007).

\subsection{Case III: 22 May 2006}

During 19-21 May 2006 the AOT measurements at ORZ and TNF agree closely with each other (Fig. 2a). Lidar measurements at ORZ and aboard the DLR Falcon, and trajectory analyses suggest the advection of a deep $(\sim 5 \mathrm{~km})$, well mixed, moderately dusty air mass from central and western Algeria (not shown). On 22 May, however, the dustiness at TNF dramatically increases, while ORZ reports fine visibility and an AOT around 0.25 (Fig. 2). The following analysis will concentrate on the extreme dust event at TNF. Data collected at ORZ are of little use for this investigation.

The interesting synoptic evolution leading to this event begins in the afternoon hours of 19 May (GD1), when deep 


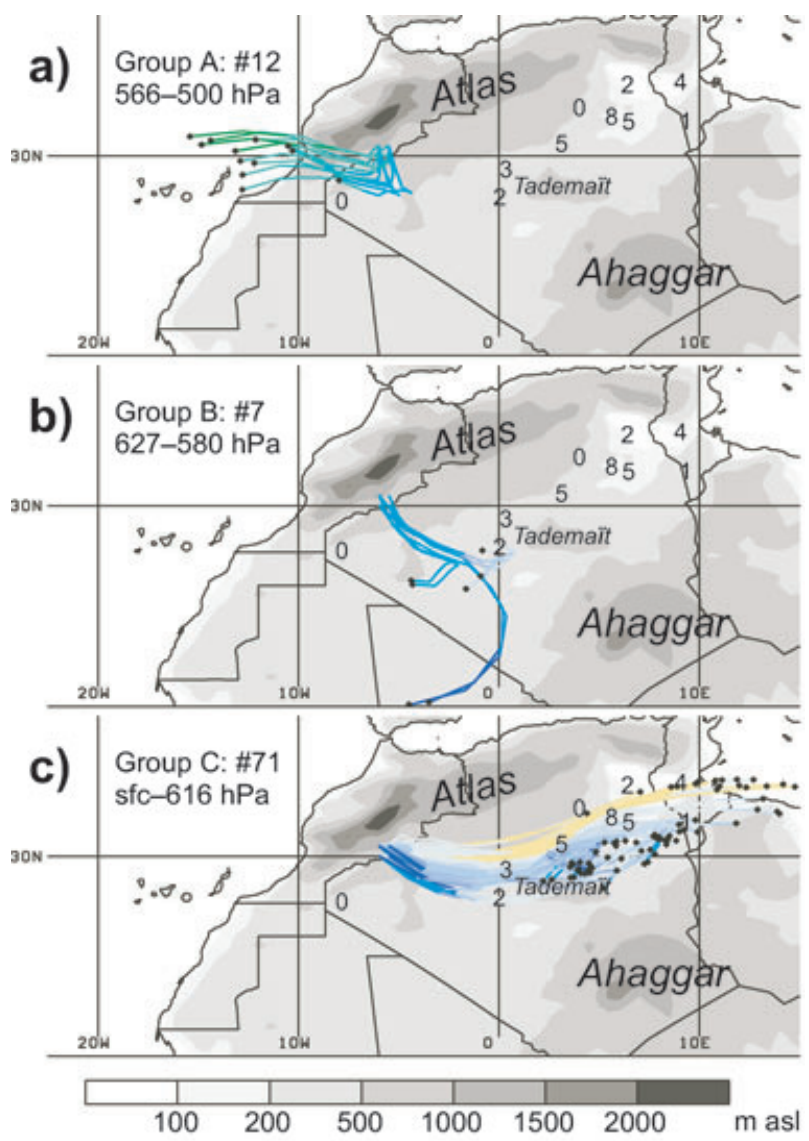

$\mathrm{hPa}$

$\begin{array}{llllllllll}300 & 380 & 460 & 540 & 620 & 700 & 780 & 860 & 940 & 1020\end{array}$

Fig. 12. Case II: As Fig. 7 but for 1200 UTC 14 May 2006.

moist convection develops over northeastern Mali. By 0000 UTC on 20 May downdrafts from this convection have formed a large haboob, whose convex leading edge quickly spreads from underneath the cirrus shield towards the north and west (Fig. 14a). At Tessalit (marked 'TS' in Fig. 14a) a mere $1 \mathrm{~mm}$ of rain is observed, suggesting substantial evaporation in the dry desert air. The main dust mobilization occurred over a practically uninhabited region in northern Mali with no surface observations. Isopleths of 300-hPa geopotential height from ECMWF analyses for 0000 UTC 20 May show a weak upper-trough over Mali (dashed line in Fig. 14b) that reduced vertical stability (not shown) and presumably supported the formation of convection. The mean sea level pressure (MSLP) and near-surface wind fields are disturbed underneath this trough showing a break in the usually zonally oriented pressure trough and two isolated divergence centres at the border triangle Mali-Niger-Burkina Faso and in the Malian Sahara (marked 'D' in Fig. 14b). There are, however, no indications for a haboob. The inspection of shortterm forecast by the ECMWF indicates that the model does not properly simulate the convection over the Sahara. Moreover there is no observational data in this region to constrain the analysis. The LM-MUSCAT-DES has problems to capture this feature also (Heinold et al., 2008).

By 1200 UTC 20 May the dusty air mass covers large parts of northern Mali and adjacent Mauritania and Algeria (Fig. 14c). On this day the upper-trough weakens and only shallow clouds form over the Sahara (not shown). On 21 May a pronounced upper-level trough approaches the Iberian Peninsula from the west. Low-level cold advection on its western side is blocked by the Atlas Mountains and leads to the formation of a lee cyclone near the border triangle Morocco-Mauritania-Algeria. The associated circulation extends the region of near-surface southerlies into Algeria and pulls the dusty air further north. By 1500 UTC moist convection has developed in this air mass (Fig. 14d), most likely supported by decreases in vertical stability due to the inflow of colder air at upper levels as indicated by the closest two radiosonde stations Tindouf and In Salah (marked in Fig. 14d; profiles not shown). In addition strong evaporation of precipitation on 19 and 20 May leads to comparably high moisture contents as revealed by a dew point of $12{ }^{\circ} \mathrm{C}$ at Tessalit at 0600 UTC 20 May. By 0000 UTC 22 May a second haboob has developed that spreads westward across western Algeria, away from the northward moving convective clouds (Fig. 14e). The fact that there are no observations of rainfall during this time points to substantial evaporation in the PBL. The ECMWF data show a distinct upper-level trough and lee cyclone over western Algeria (Fig. 14f). The southerly winds at its eastern edge push the moist air and the convection northwards. Again there are no clear indications of a haboob, which is consistent with a failure of the ECMWF forecast model to properly simulate the convection over the Sahara (not shown).

The impacts of the convection are felt quite dramatically at several stations in the region. Between 18 and 21 UTC on 21 May visibility drops from 10 to $1 \mathrm{~km}$ at Adrar (marked in Figs. $14 \mathrm{~d}$ and e) accompanied by winds of $16 \mathrm{~m} \mathrm{~s}^{-1}$, dust mobilization and a pronounced increase in dew point (not shown). Around 0400 UTC the density current reaches TNF as indicated by a sudden rise in dew point $\left(3.5{ }^{\circ} \mathrm{C}\right.$ in $6 \mathrm{~min}$, not shown) and a dramatic decrease in visibility from 20 to $1.5 \mathrm{~km}$ (Fig. 2b). The VIS satellite image at 0600 UTC shows the dust front reaching across western Algeria into southern Morocco (Fig. 15). In the course of the day the whole system drifts eastward, and moist and dusty conditions reach Beni Abbes (0900 UTC), Timimoun (1200 UTC) and Bechar (1500 UTC). A striking feature in Fig. 15 is the large anticyclonically curved cirrus shield over Algeria that is reminiscent of the outflow spirals of a tropical cyclone. Satellite animations show that, while the bulk of the clouds rotate cyclonically around the lee cyclone to the west, the near-tropopause convective outflow spreads into the region of anticyclonic shear along the southeastern part of the large upper-level trough over the Iberian Peninsula (see the associated frontal band stretching into Morocco in Fig. 15). It has been suggested that the weak inertial stability associated with such a configuration facilitates the ventilation of outflow 

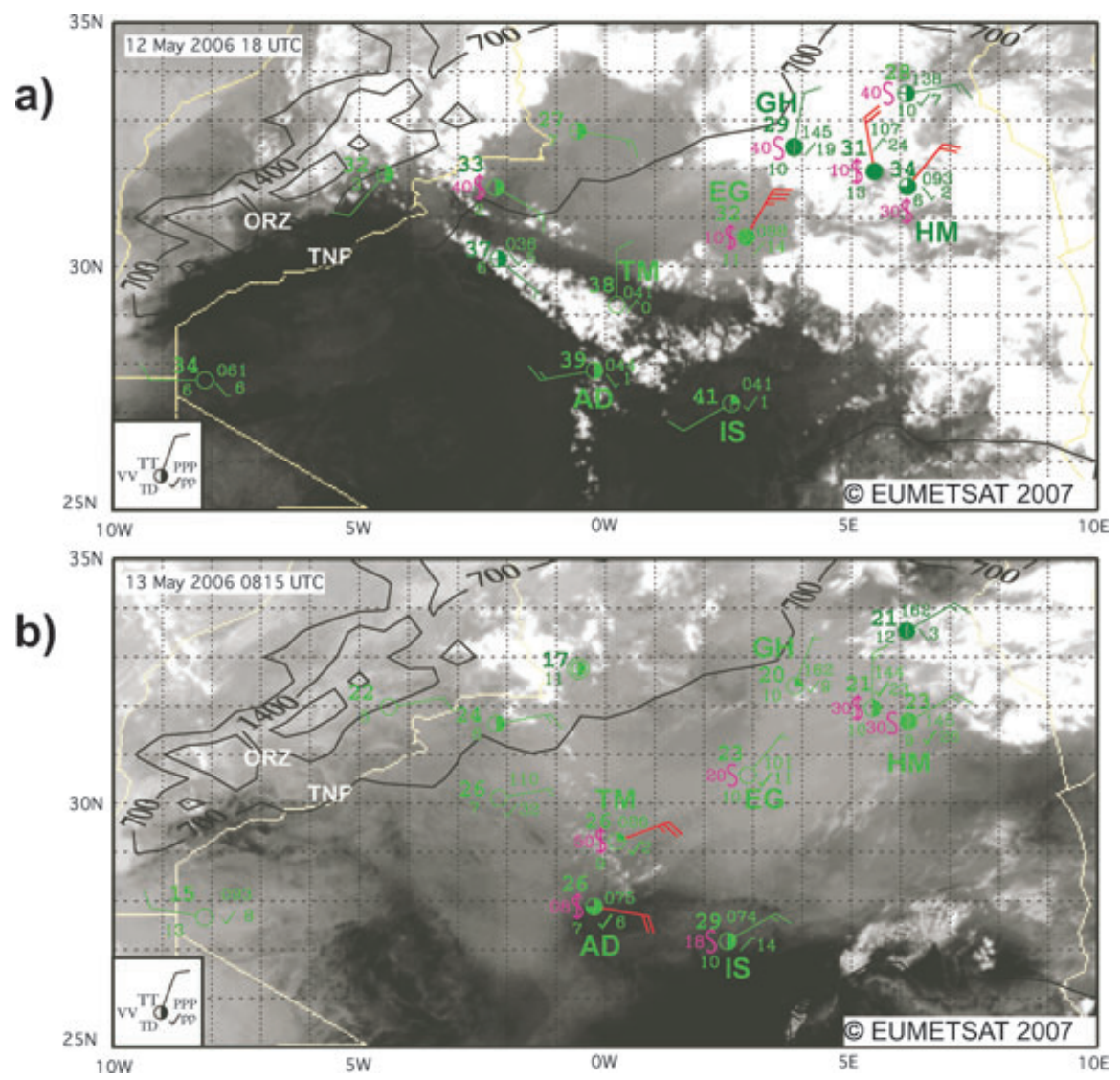

Fig. 13. Case II: As Fig. 8 but for (a) IR image and station observations at 1800 UTC 12 May 2006 and (b) IR image at 0815 UTC and station observations at 0600 UTC on 13 May 2006. Note that some stations did not report dew points.

and thereby favours convective intensification (Blanchard et al., 1998).

The problems with the representation of the haboobs on 1920 and 21-22 May in the ECMWF model imply that a dust source identification based on trajectories may be problematic in this case. In fact trajectories calculated analogously to Figs. 7 and 12 point to a westward dust transport from central Algeria, while satellite images suggest a mobilization over western Algeria and a northward transport to TNF in connection with the second haboob (Fig. 14e). It is conceivable that dust raised over the Malian Sahara on 20 May is mixed into the air mass reaching TNF on 22 May. Samples taken at the ground and in the atmosphere on this day have unusually low calcium and high silicate contents in strong contrast to Cases I and II (fig. 17 in Kandler et al., 2008). This is consistent with sources in western Algeria and northern Mali. The LM-MUSCAT-DES equally struggles to reproduce the involved moist convective dynamics (Heinold et al., 2008) and cannot be used to clarify sources and transports.

\section{Summary and conclusions}

We have analysed meteorological conditions for dust mobilization and transport in northern Africa using the observations taken during the SAMUM field campaign in southern Morocco in May/June 2006, together with satellite, gridded analysis and weather station data. The processes investigated include horizontal transports by meso- and synoptic-scale circulations, and vertical mixing processes in the PBL. The results provide a basis for the evaluation of numerical models, and for the interpretation of the mineralogical composition and optical properties of dust samples.

Measurements of AOT and visibility at the two SAMUM sites ORZ and TNF reveal large day-to-day variations and sometimeslarge regional-scale differences. The latter is most likely due to the lower elevation of TNF and stronger local sources, as well as a shielding of the ORZ site from Saharan air masses through the Jebel Saghro and Anti-Atlas Mountains. With respect to vertical transports of dust in the PBL, lidar and radiosonde observations at ORZ reveal two important processes: (1) During stable nighttime and morning conditions differential advection within the near-surface layer and the residual layer aloft can transport different air masses to the site. (2) On most clear days dry convection during the morning hours erodes the residual layer until mid-day when often cumulus clouds form near the base of the FT. The vigorous vertical mixing can homogenize the air as deep as $4-5 \mathrm{~km}$ agl. This process limits the back tracing 

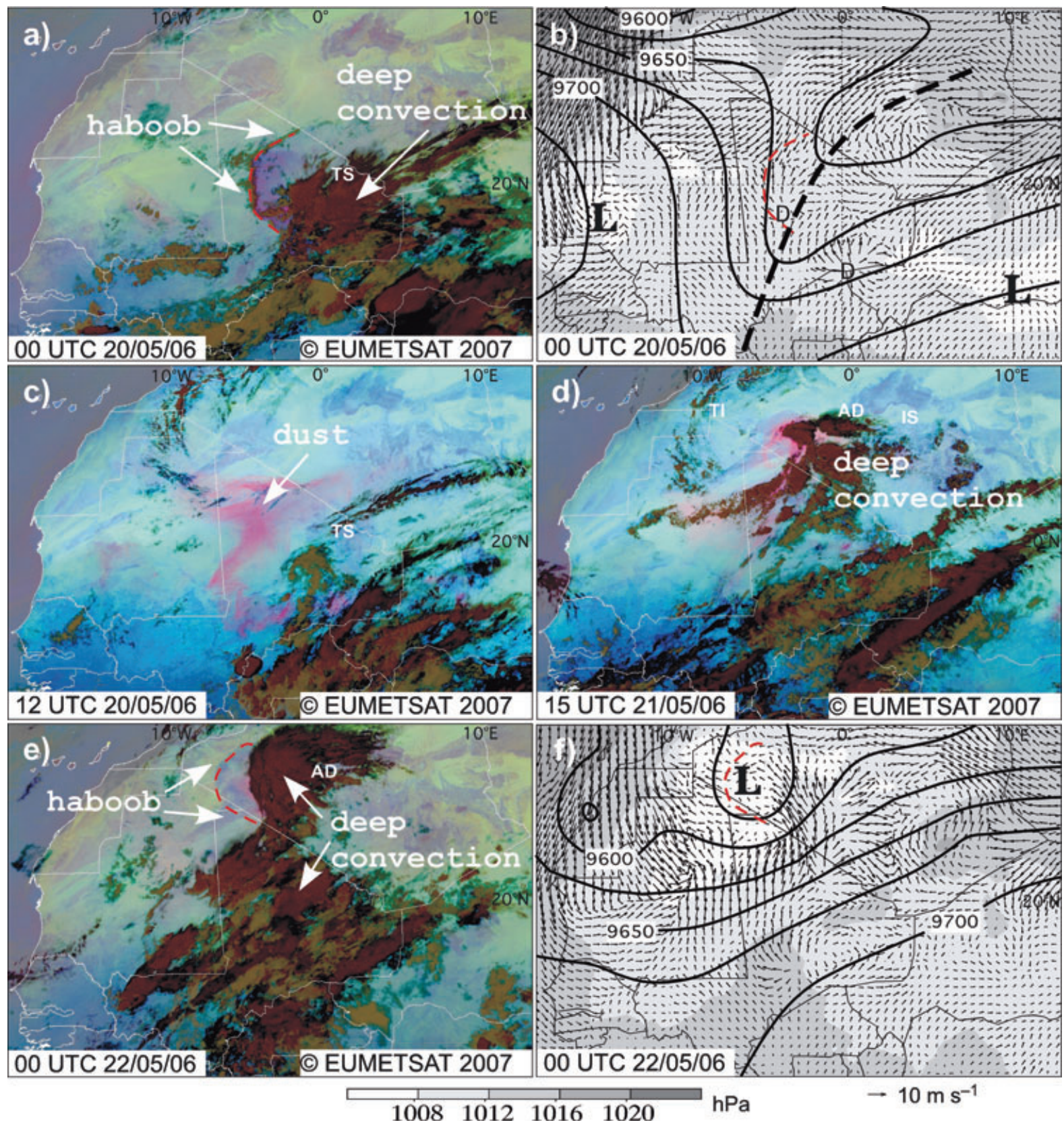

1008101210161020

Fig. 14. Case III: Meteosat Second Generation dust product for (a) 0000 UTC 20 May, (c) 1200 UTC 20 May, (d) 1500 UTC 21 May and (e) 0000 UTC 22 May 2006. Magenta colours indicate dust, dark red colours cold, thick high-level clouds and brown colours thick mid-level clouds. (b) and (f) show ECMWF analysis data for the times shown in (a) and (e), respectively. Displayed variables are geopotential height at $300 \mathrm{hPa}$ (thick lines contoured every $25 \mathrm{gpm}$ ), mean sea level pressure (in hPa, grey shaded) and wind vectors on the lowest model level. Low-pressure centres are marked with ' $\mathrm{L}$ ' and dashed red lines indicate the dust fronts identified on the satellite images. In (b) a thick dashed line marks the axis of an upper-level trough and 'D's mark near-surface divergence centres. The locations of synoptic stations mentioned in the text are marked on the dust images (for more information, see Table 1).

of dust events to one single source region and emission event with trajectory calculations based on gridpoint wind fields. It would be worthwhile to compare the results presented here with Lagrangian particle dispersion models that better account for mixing processes.
Several DPs and IPs were identified during SAMUM, which are closely tied to changes in the large-scale circulation. The most important emission events occurred in the lowlands between western Tunisia and central Algeria. At least in two cases, enhanced calcium contents and Angström exponents in dust 


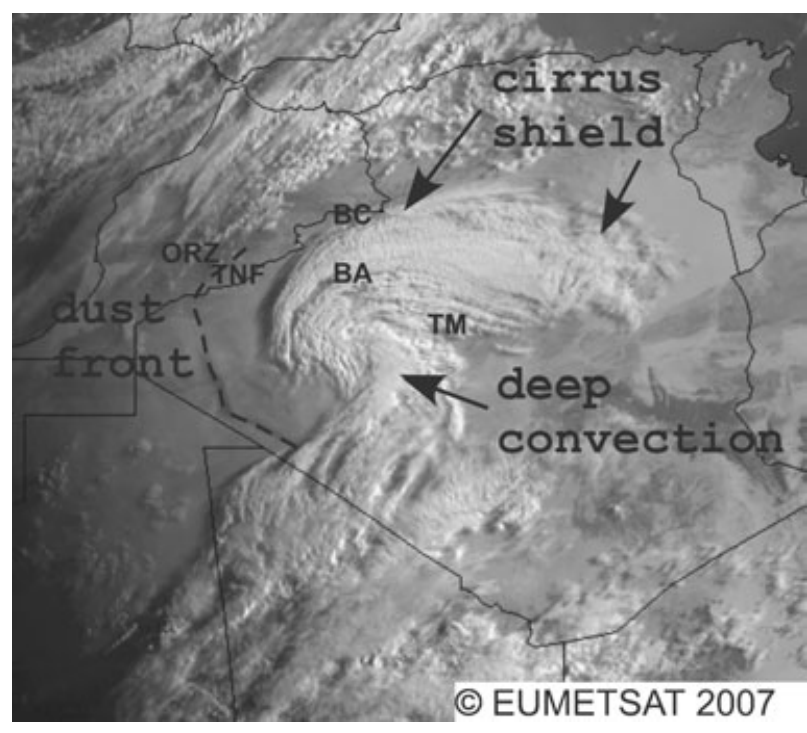

Fig. 15. Case III: Meteosat Second Generation VIS image at 0600 UTC 22 May 2006. Several synoptic stations (see Table 1 for abbreviations) and the SAMUM sites ORZ and TNF are marked. The dust front is indicated with a dashed line.

samples over Morocco corroborate an advection from the salt pans within this region. The most significant dust events are related to the eastward passage of upper-level short-waves across northwestern Africa accompanied by lee cyclogenesis south of the Atlas (Pedgley, 1972). When these lee cyclones reach eastern Algeria, cool air from the Mediterranean surges into the continent along their northern flanks, associated with falling temperatures, rising pressure, high winds, dust mobilization and low visibility. In one case this air mass was cooled further by the evaporation of convective precipitation. The subsequent formation of a ridge over northwestern Africa leads to the advection of this air into southern Morocco and finally, to more quiescent and less dusty conditions. This type of evolution is satisfactorily reproduced by the regional dust model LM-MUSCAT-DES (Heinold et al., 2008).

In addition, local dust emissions occurred in connection with a pronounced cut-off low over Morocco around 25 May 2006 and with meso-scale density currents generated by evaporation of afternoon convective precipitation from the Atlas Mountains (Knippertz et al., 2007). Dust devils and dust uplift by convective plumes have also been observed, especially during the IPs of SAMUM (Ansmann et al., 2008b). A particularly interesting event is the penetration of a fairly moist and dusty air mass from northern Mali into southern Morocco in connection with a weak lee cyclone and the repeated formation of haboobs. This event is unsatisfactorily represented in both the LM-MUSCAT-DES and in operational ECMWF analysis wind fields. It appears that the models struggle to initiate convection over the Sahara. Therefore, the most urgent research need regarding the meteorology of dust emission and transport in northern Africa is the role of moist convection and its representation in numerical models. More surface and upper-air observations from this region and studies investigating the sensitivity to convection schemes, microphysics and PBL processes will help to make improvements in this important issue, which appears crucial for both the moisture budget and the dust cycle over the Sahara during the summer half year.

\section{Acknowledgments}

The SAMUM researcher group is funded by the German Science Foundation (DFG) under Grant FOR539. The first author is currently sponsored through the DFG Emmy Noether program (Grant KN 581/2-3) and his participation in the field campaign was supported through the Forschungsfond of the University of Mainz, which also provided funds for radiosondes. We are grateful to the Direction de la Météorologie Nationale du Maroc for providing the station data from ORZ. We would like to thank Andreas H. Fink, Volker Ermert, Ralf Hoffmann and Kai Born from the University of Cologne for their help with processing the radiosonde data, for creating Fig. 1 and for information on the visibility measurements at ORZ. We acknowledge the valuable comments of Harald Sodemann, Baruch Ziv and John Marsham, which helped to substantially improve an earlier version of the paper.

\section{References}

Alpert, P. and Ziv, B. 1989. The Sharav Cyclone: observations and some theoretical considerations. J. Geophys. Res. 94, 18495-18514.

Althausen, D., Müller, D., Ansmann, A., Wandinger, U., Hube, H. and co-authors. 2000. Scanning 6-wavelength 11-channel aerosol lidar. J. Atmos. Oceanic Technol. 17, 1469-1482.

Ansmann, A., Tesche, M., Althausen, D., Müller, D., Seifert, P. and co-authors. 2008a. Influence of Saharan dust on cloud glaciation in southern Morocco during the Saharan Mineral Dust Experiment. $J$. Geophys. Res. 113, D04210, doi:10.1029/2007JD008785.

Ansmann, A., Tesche, M., Knippertz, P., Bierwirth, E., Althausen, D. and co-authors. 2008b. Vertical profiling of convective dust plumes in southern Morocco during SAMUM. Tellus 61B, doi: 10.1111/j.16000889.2008.00384.x.

Bierwirth, E., Wendisch, M., Ehrlich, A., Heese, B., Otto, S. and coauthors. 2008. Spectral surface albedo over Morocco and its impact on the radiative forcing of Saharan dust. Tellus 61B, doi: 10.1111/j.16000889.2008.00395.x.

Blanchard, D. O., Cotton, W. R. and Brown, J. M. 1998. Mesoscale circulation growth under conditions of weak inertial instability. Mon. Wea. Rev. 126, 118-140.

Bou Karam, D., Flamant, C., Knippertz, P., Reitebuch, O., Pelon, J., Chong, M. and Dabas, A. 2008. Dust emissions over the Sahel associated with the West African Monsoon inter-tropical discontinuity region: a representative case study. Quart. J. Roy. Meteorol. Soc. 134, $621-634$. 
Carson, D. J. 1973. The development of a dry inversion-capped convectively unstable boundary layer. Quart. J. Roy. Meteorol. Soc. 99, 450-467.

Chen, W. and Fryrear, D. W. 2002. Sedimentary characteristics of a haboob dust storm. Atmos. Res. 61(1), 75-85.

Dinter, T., von Hoyningen-Huene, W., Burrows, J. P., Kokhanovsky, A., Bierwirth, E., Wendisch, M., Müller, D., Kahn, R. and Diouri, M. 2008. Retrieval of aerosol optical thickness for desert conditions using MERIS observations during the SAMUM campaign. Tellus 61B, doi: 10.1111/j.1600-0889.2008.00391.x.

Egger, J., Alpert, P., Tafferner, A. and Ziv, B. 1995. Numerical experiments on the genesis of Sharav cyclones: idealized simulations. Tellus 47A, 162-174.

El Fandy, M. G. 1940. The formation of depressions of the Khamsin type. Quart. J. R. Meteorol. Soc. 66, 323-336.

Esselborn, M., Wirth, M., Fix, A., Weinzierl, B., Rasp, K. and co-authors. 2008. Spatial distribution and optical properties of Saharan dust observed by airborne high spectral resolution lidar during SAMUM 2006. Tellus 61B, doi: 10.1111/j.1600-0889.2008.00394.x.

Flamant, C., Chaboureau, J.-P., Parker, D. P., Taylor, C. M., Cammas, J. P. and co-authors. 2007. Airborne observations of the impact of a convective system on the planetary boundary layer thermodynamics and aerosol distribution in the inter-tropical discontinuity region of the West African Monsoon. Quart. J. R. Meteorol. Soc. 133, 11751189.

Gamo, M. 1996. Thickness of the dry convection and large-scale subsidence above deserts. Bound. Lay. Meteorol. 79, 265-278.

Heinold, B., Tegen, I., Esselborn, M., Kandler, K., Knippertz, P. and coauthors. 2008. Regional Saharan dust modelling during the SAMUM 2006 campaign. Tellus 61B, doi: 10.1111/j.1600-0889.2008.00387.x.

Heintzenberg, J. 2008. The SAMUM-1 experiment over Southern Morocco: overview and introduction. Tellus 61B, doi: 10.1111/j.16000889.2008.00403.x.

Holben, B. N., Eck, T. F., Slutsker, I., Tanré, D., Buis, J. P. and coauthors. 1998. AERONET — a federated instrument network and data archive for aerosol characterization. Rem. Sens. Environ. 66, 1-16.

Idso, S. B., Ingram, R. S. and Pritchard, J. M. 1972. An American haboob. Bull. Am. Meteorol. Soc. 53, 930-933.

Kalu, A. E. 1979. The African dust plume: its characteristics and propagation across West Africa in winter. In: Saharan Dust (ed. C. Morales). J. Wiley and Sons, Chichester, 95-118

Kandler, K., Schütz, L., Deutscher, C., Ebert, M., Hofmann, H., Jäckel, S. and co-authors. 2008. Size distribution, mass concentration, chemical and mineralogical composition, and derived optical parameters of the boundary layer aerosol at Tinfou, Morocco, during SAMUM 2006. Tellus 61B, doi: 10.1111/j.1600-0889.2008.00384.x.

Knippertz, P. and Fink, A. H. 2006. Synoptic and dynamic aspects of an extreme springtime Saharan dust outbreak. Quart. J. R. Meteorol. Soc. 132, 1153-1177.

Knippertz, P., Deutscher, C., Kandler, K., Müller, T., Schulz, O. and co-authors. 2007. Dust mobilization due to density currents in the Atlas region: observations from the SAMUM 2006 field campaign. $J$. Geophys. Res. 112, D21109, doi:10.1029/2007JD008774.

Koch, J. and Renno, N. O. 2005. The role of convective plumes and vortices on the global aerosol budget. Geophys. Res. Lett. 32, L18806, doi:10.1029/2005GL023420.
Lawson, T. J. 1971. Haboob structure at Khartoum. Weather 26, 105112.

Membery, D. A. 1985. A gravity-wave haboob? Weather 40, 214 221.

Miller, R. L. and Tegen, I. 1999. Radiative forcing of a tropical direct circulation by soil dust aerosols. J. Atmos. Sci. 56, 2403-2433.

Miller, S. D., Kuciauskas, A. P., Liu, M., Ji, Q., Reid, J. S. and coauthors. 2008. Haboob dust storms of the southern Arabian Peninsula. J. Geophys. Res. 113, D01202, doi:10.1029/2007JD008550.

Müller, T., Schladitz, A., Maßling, A., Kaaden, N., Wiedensohler, A. and co-authors. 2008. Spectral absorption coefficients and imaginary parts of refractive indices of Saharan dust during SAMUM-1. Tellus 61B, doi: 10.1111/j.1600-0889.2008.00399.x.

Oke, A. M. C., Tapper, N. J. and Dunkerley, D. 2007. Willy-willies in the Australian landscape: the role of key meteorological variables and surface conditions in defining frequency and spatial characteristics. $J$. Arid Environ. 71, 201-215.

Parker, D. P., Burton, R. R., Diongue-Niang, A., Ellis, R. J., Felton, M. and co-authors. 2005. The diurnal cycle of the West African monsoon circulation. Quart. J. R. Meteorol. Soc. 131, 2839-2860.

Pedgley, D. E. 1972. Desert depression over northeast Africa. Meteorl. Mag. 101, 228-244.

Petzold, A., Rasp, K., Weinzierl, B., Esselborn, M., Hamburger, T. and co-authors. 2008. Saharan dust absorption and refractive index from aircraft-based observations during SAMUM 2006. Tellus 61B, doi: 10.1111/j.1600-0889.2008.00383.x.

Schepanski, K., Tegen, I., Laurent, B. Heinold, B. and Macke, A. 2007. A new Saharan dust source activation frequency map derived from MSG-SEVIRI IR-channels. Geophys. Res. Lett. 34, L18803, doi:10.1029/2007GL030168.

Schladitz, A., Müller, T., Kaaden, N., Massling, A., Kandler, K. and co-authors. 2008. In situ measurements of optical properties at Tinfou (Morocco) during the Saharan Mineral Dust Experiment SAMUM 2006. Tellus 61B, doi: 10.1111/j.1600-0889.2008.00397.x.

Slingo, A., Ackerman, T. P., Allan, R. P., Kassianov, E. I., Mcfarlane, S. A. and co-authors. 2006. Observations of the impact of a major Saharan dust storm on the atmospheric radiation balance. Geophys. Res. Lett. 33, L24817, doi:10.1029/2006GL027869.

Sodemann, H., Palmer, A. S., Schwierz, C., Schwikowski, M. and Wernli, H. 2006. The transport history of two Saharan dust events archived in an Alpine ice core. Atmos. Chem. Phys. 6, 667-688.

Stensrud, D. J. 1996. Importance of low-level jets to climate: a review. J. Clim. 9, 1698-1711.

Sutton, L. J. 1925. Haboobs. Quart. J. R. Meteorol. Soc. 51, 25-30.

Tesche, M., Ansmann, A., Müller, D., Althausen, D., Mattis, I. and coauthors. 2008. Vertical profiling of Saharan dust with Raman lidars and airborne HSRL during SAMUM. Tellus 61B, doi: 10.1111/j.16000889.2008.00390.x.

Warner, T. 2004. Desert Meteorology. Cambridge University Press, Cambridge, U.K.

Washington, R. and Todd, M. C. 2005. Atmospheric controls on mineral dust emission from the Bodélé Depression, Chad: the role of the low level jet. Geophys. Res. Lett. 32, L17701, doi:10.1029/2005GL023597.

Weinzierl, B., Petzold, A., Esselborn, M., Wirth, M., Rasp, K. and co-authors. 2008. Airborne measurements of dust layer properties, 
particle size distribution and mixing state of Saharan dust during SAMUM 2006. Tellus 61B, doi: 10.1111/j.1600-0889.2008.00392.x.

Wernli, H. and Davies, H. C. 1997. A Lagrangian-based analysis of extratropical cyclones. I: the method and some applications. Quart. J. R. Meteorl. Soc. 123, 467-489.

WMO. 1995. Manual on codes. In: International Codes, Part A-
Alphanumeric Codes. WMO-No. 306. Volume I.1. World Meteorological Organization, Geneva, Switzerland, 169 pp.

Yaalon, D. H. and Ganor, E. 1979. East Mediterranean trajectories of dust-carrying storms from the Sahara and Sinai. In: Saharan Dust (ed. C. Morales). J. Wiley and Sons, Chichester, 187193. 